\title{
La sombra monetaria del déficit en la España de la peseta
}

\section{Monetary shadow of deficit, Spain 1874-1998}

\author{
REGINA ESCARIO \\ MARCELA SABATÉ \\ MARÍA DOLORES GADEA \\ Universidad de Zaragoza
}

\begin{tabular}{|c|c|}
\hline RESUMEN & ABSTRACT \\
\hline $\begin{array}{r}\text { De acuerdo con la historiografía, el } \\
\text { predominio del déficit presupuestario } \\
\text { condicionó de manera recurrente la creación } \\
\text { de dinero en la España de la peseta. Las } \\
\text { contribuciones del componente público al } \\
\text { crecimiento de la base monetaria entre } 1874 \text { y } \\
1998 \text { respaldan parcialmente esta idea. Una } \\
\text { idea que aquí se confirma, al hallar una } \\
\text { relación causal dinámica de saldo } \\
\text { presupuestario hacia crecimiento monetario } \\
\text { para el conjunto del periodo. El } \\
\text { debilitamiento de la relación entre saldo y } \\
\text { base monetaria identifica 1984 como el fin del } \\
\text { seigniorage en España. Hay que esperar hasta } \\
\text { los noventa para que el debilitamiento de la } \\
\text { relación entre saldo presupuestario y una } \\
\text { definición más amplia de dinero (Activos en } \\
\text { Manos del Público, ALPs), acuse el esfuerzo } \\
\text { de convergencia nominal que precedió a la } \\
\text { integración de la peseta en el euro. }\end{array}$ & $\begin{array}{l}\text { According to the literature, the predominance } \\
\text { of budget deficits conditioned money growth } \\
\text { in Spain while the peseta was its currency. } \\
\text { The idea of a long-running fiscal interference } \\
\text { in monetary dynamics is partly backed by the } \\
\text { contribution of the public component to } \\
\text { monetary base growth in 1874-1998. This } \\
\text { paper confirms the existence of this } \\
\text { interference by finding a long-running causal } \\
\text { relationship between budget and money for } \\
\text { the whole period. The weakening of causality } \\
\text { between budget and the monetary base } \\
\text { allows us to locate the end of seigniorage in } \\
\text { Spain in the mid-1980s. It is not until the } \\
\text { 1990s that the weakening of causality } \\
\text { between budget and a broader definition of } \\
\text { money (Liquid Assets held by the Public) } \\
\text { reflected the efforts towards nominal } \\
\text { convergence prior to joining the European } \\
\text { Monetary Union. }\end{array}$ \\
\hline PALABRAS CLAVE: Déficit, Dinero & KEYWORDS: Deficit, Money \\
\hline Códigos JEL: E5, H6, N1 & JEL Codes: E5, H6, N1 \\
\hline
\end{tabular}




\section{Introducción ${ }^{1}$}

La intensidad de la actual crisis ha devuelto el déficit público al centro de la arena económica española. Tras el ajuste realizado para acceder en 1998 a la Unión Económica y Monetaria (UEM), sólo una década de respiro ha dado el presupuesto a la España del euro. $Y$ decimos respiro porque, si bien en un contexto y con unas reglas de juego completamente distintas, la cuestión del déficit ya ocupó una posición central en la España de la peseta. Nos referimos a la idea, bien presente en la literatura, de que desde 1874, cuando el Banco de España obtuvo el monopolio de emisión, hasta los ajustes requeridos para la integración monetaria, el saldo presupuestario condicionó de forma recurrente la creación de dinero. El informe sobre el patrón oro elaborado por Flores de Lemus y los análisis de Olariaga y Sardá insistieron en el hecho de que entre 1874 y 1935, cuando fue necesario, el control de precios se sacrificó a la financiación del Tesoro². Más recientemente, Martín Aceña aproximaba el alcance de las interferencias presupuestarias mediante el cálculo de las contribuciones sectoriales (sectores público, privado y exterior) al crecimiento de la base monetaria hasta $1935^{3}$. En última instancia, Sabaté et al. confirmaban econométricamente la existencia de una relación de causalidad de déficit a base monetaria entre 1874 y $1935^{4}$.

En cuanto a la etapa posterior a la Guerra Civil, la idea de que el saldo presupuestario marcó la evolución de la política monetaria sigue presente en la literatura. El mismo argumento de dominio fiscal aparece en un trabajo de González relativo al periodo autárquico del franquismo y en un estudio de Poveda para los años sesenta ${ }^{5}$. Las interferencias monetarias de la financiación del déficit en los años setenta y ochenta, hasta que en 1994 el Banco de España consigue la autonomía monetaria, son destacadas, entre otros, por Rojo, Ortega, Malo de Molina o Fuentes Quintana ${ }^{6}$. Para este último, esas continuas interferencias, sumadas a las registradas entre 1874 y 1935, constituyeron un rasgo esencial del "modelo castizo" de desarrollo económico español ${ }^{7}$.

Sin embargo, falta hasta la fecha un análisis que cubra todo el período. Y éste es precisamente el objeto de estas páginas, que pretenden ofrecer una visión global de las injerencias fiscales, ampliando la cobertura temporal de Sabaté et al., para incluir el análisis de la relación presupuesto-dinero tras la Guerra Civil ${ }^{8}$. Se empieza exten-

\footnotetext{
[Fecha de recepción del original, 17 de diciembre de 2009. Versión definitiva, 25 de junio de 2010] Este trabajo se ha beneficiado del apoyo financiero concedido por el proyecto MICINN ECO-2008 03040 y por el programa del Grupo de Excelencia de Investigación SEIM (SEC 269-124).

Flores de Lemus (1929); Olariaga (1933) y Sardá (1948).

Martín Aceña (1985a, b).

Sabaté, Gadea y Escario (2006).

González (1979) y Poveda (1972).

Rojo (2002, 2004); Ortega (1984, 1987a, b); Malo de Molina (2003) y Fuentes Quintana (1995, 1996).

Véase Fuentes (1995), p. 53.

Sabaté, Gadea y Escario (2006).
} 
diendo el cálculo de las contribuciones del sector público al crecimiento de la base monetaria para cubrir la totalidad del período 1874-1998. Además de esta ampliación temporal, como novedad sobre el ejercicio que Martín Aceña realizó para 1900$1935^{9}$, se revisa el cálculo de la contribución del componente público a la creación de base monetaria para incluir la velada influencia del déficit (vía pignoración o redescuento) sobre el componente privado de creación de base ${ }^{10}$.

En el apartado 2 se concretan las fuentes y métodos utilizados en los cálculos de las contribuciones. Estos cálculos, en términos absolutos y relativos, periodificados en función de los acontecimientos fiscales y monetarios más relevantes, se ofrecen en el apartado 3 y confirman, cuando la pignoración de la deuda se imputa al Estado, una activa contribución del sector público al crecimiento de la base monetaria. Esta contribución se sostiene desde 1874 hasta mediados de los ochenta del siglo Xx, con las únicas excepciones de la estabilización villaverdista tras el Desastre de 1898 y el Plan de Estabilización y Liberalización de 1959. Sin embargo, aunque a mediados de los ochenta el déficit deja de proyectar su sombra sobre la base monetaria, la literatura sostiene que siguió interfiriendo en la creación de dinero por vía de la emisión de títulos de deuda a muy corto plazo (Pagarés y Letras), que en la práctica operaban como medio de pago. Estos títulos computaban en una definición más amplia de dinero, los Activos Líquidos en manos del Público (ALP), que en 1984 se convirtieron en la variable de control monetario para el Banco de España. Nuestros cálculos ilustran cómo Pagarés y Letras explican una parte sustancial del crecimiento de los ALP hasta 1989.

De esta manera, todo apunta a que, por una u otra vía (base monetaria o emisión de deuda líquida), el déficit habría condicionado la creación de dinero en la España de la peseta. El apartado 4 confirma dinámicamente la existencia de dicha relación. Primero, para el total del período 1874-1998, hallamos una relación de largo plazo entre déficit y base monetaria, siempre con el sentido de causalidad claramente definido de la primera a la segunda variable. Además, hallamos que la intensidad del vínculo se debilita de 1984 en adelante, señalando la por entonces renuncia a seguir financiando el déficit con recurso directo al Banco de España, o en otras palabras, señalando el fin del seigniorage. Segundo, para el total del período 1874-1998, hallamos la misma relación de causalidad a largo plazo entre déficit y ALP. Pero ahora, también de acuerdo con la literatura, encontramos que la intensidad del vínculo no registra inflexión alguna en los ochenta, en consonancia con

\footnotetext{
$9 \quad$ Martín Aceña (1985a, b).

10 A partir de 1917 y hasta 1959, la deuda pública colocada en manos privadas, especialmente de la banca, podía ser automáticamente pignorada en el Banco de España a un tipo de interés inferior al de su rendimiento. Al término de su emisión, entre 1962 y 1970, la figura del redescuento especial autorizó el descuento automático en el Banco de España, a un tipo también inferior al de descuento, para los efectos que canalizaban financiación privilegiada hacia los sectores declarados de desarrollo prioritario.
} 
la proliferación de títulos de deuda a corto plazo que, emitidos para financiar el déficit, computan en esta más amplia definición del dinero. En este caso, el nexo no se debilita hasta que en los noventa, la voluntad española de cumplir con los requisitos de Maastricht conlleva un importante recorte de las necesidades de financiación pública. Al hilo de estos resultados, el apartado 5 concluye reafirmando el papel del déficit como condicionante secular del devenir monetario en la España de la peseta.

\section{Presentación de datos, cálculo de contribuciones y fuentes}

El Gráfico 1 ofrece una primera intuición de la hipótesis de que a largo plazo ha existido una relación negativa entre saldo presupuestario e incremento de la base monetaria en la España contemporánea. Así, la dinámica del saldo se percibe, a grandes rasgos, como la inversa de la variación de la cantidad de dinero, actuando el eje de abscisas como un espejo para las series fiscal y monetaria. Periodos con déficit han coincidido con periodos de creación monetaria, y viceversa, los breves periodos en que las cuentas se saldaron con superávit (o con minoración del déficit), la cantidad de dinero se contrajo (o al menos, disminuyó su crecimiento) ${ }^{11}$. De ahí la idea, ampliamente presente en la literatura, acerca de que la política fiscal influyó recurrentemente sobre el devenir monetario de la España contemporánea.

De una forma más concreta, esta intuición se ha igualmente apoyado en el cálculo de las contribuciones del componente público al crecimiento de la base monetaria. Como es sabido, este crecimiento se puede definir como la suma del crecimiento de cada uno de sus componentes, es decir, según el crecimiento de la base sea generado por el sector público, por el sector privado o por el exterior. En distintos momentos, la literatura ha denunciado el crecimiento del crédito del banco emisor al sector público como determinante clave en la expansión de la base monetaria. A efectos de ilustrar esta contribución pública a la creación de base hemos procedido a su cálculo para el conjunto del período 1875-1998, fragmentándolo en subperíodos, delimitados éstos por los cambios registrados en la historia fiscal y monetaria española a lo largo de esos más de cien años.

11 Tres periodos enturbian, aparentemente, la relación inversa entre presupuesto y dinero. El primero, durante los años del conflicto colonial en Cuba (1896-98), cuando los gastos militares quedaron sin ser oficialmente registrados. En segundo lugar, durante los años 50 y 60, momento en que los grandes déficit generados por los Organismos Autónomos fueron computados extraoficialmente, haciendo coincidir aparentes equilibrios presupuestarios y expansión monetaria. Por último, los llamativos déficit de los noventa, sin reflejo en la base, al haber sido sustituido la monetización por la emisión de títulos. Sobre estas cuestiones se trata más detalladamente en el próximo apartado. 


\section{GRÁFICO 1}

EVOLUCIÓN DE LA RELACIÓN ENTRE SALDO PRESUPUESTARIO Y VARIACIÓN DE BASE MONETARIA: 1875-1998

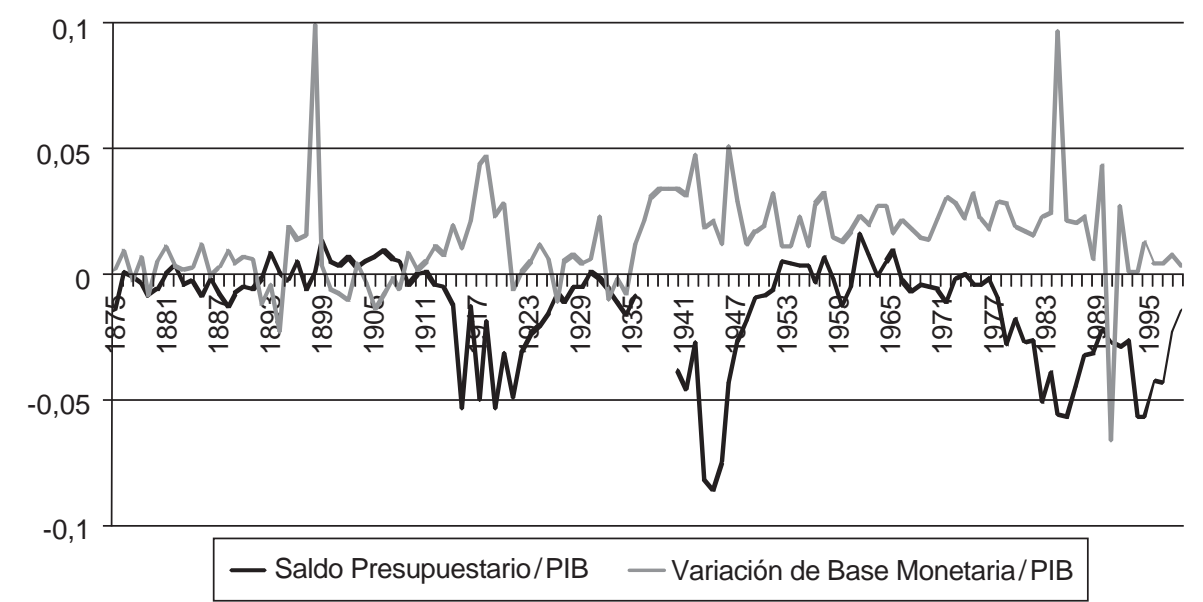

Fuentes: Véase Sección 2.

Las tasas anuales de crecimiento de la base monetaria y otros activos se calculan como $\left(x_{t}-x_{t-1}\right) / x_{t-1}$, mientras que las tasas de crecimiento por subperiodos se obtienen como promedios de las anteriores. En los Cuadros 1a y 2a, las contribuciones sectoriales se calculan como el incremento de cada componente relativizado por la base monetaria, esto es, $c\left(x_{t}\right)=\left(x_{t}-x_{t-1}\right) / b m_{t-1}$, de forma que la suma de las contribuciones es igual al crecimiento total de la base. La contribución que figura como c(otros) surge como diferencia entre la base monetaria y la suma de los sectores exterior, público y privado. Esta suma no siempre alcanza el total de la base puesto que en determinados periodos hay operaciones no sectorizadas $u$ otras rúbricas residuales. En los Cuadros $1 b$ y $2 b$ se relativizan las contribuciones sectoriales de cada subperiodo por la tasa de crecimiento de la base monetaria en el mismo subperiodo, de manera que la suma totaliza el $100 \%$ de su crecimiento ${ }^{12}$.

Además, tal y como detallamos en el próximo apartado, el sector público interfirió en distintos momentos en la generación de base monetaria estimulando, vía pignoración de deuda o redescuento especial, la expansión del crédito privado. Por este motivo, a efectos de matizar el vínculo déficit-dinero, se calculan también las llamadas contribuciones del sector público ampliado, añadiendo al componente sector público la pignoración de la deuda (entre 1917 y 1959) y el redescuento especial

12 Cabe advertir que, cuando la tasa de crecimiento de la base monetaria es negativa (primer decenio del siglo $\mathrm{XX}$ ), una contribución sectorial positiva indica que el sector correspondiente contribuye a esa reducción. 
(entre 1962 y 1970); en estos casos, la pignoración y el redescuento se sustraen de la contribución del sector privado (de esta forma restringido).

En cuanto a las fuentes, los datos del primer subperiodo 1874-1900 proceden de los balances del Banco de España reconstruidos por Anes ${ }^{13}$. El componente público se obtuvo añadiendo la moneda de plata, para homogeneizar con las fuentes disponibles para el resto de periodos ${ }^{14}$. Para los subperiodos 1900-1935 y 1940-1962 se utilizaron cifras de Martín Aceña ${ }^{15}$. Para los años 1962-1981 se utilizaron las Series Históricas del Banco de España (1982), donde la contribución del sector privado se corresponde con la partida Operaciones con el sistema bancario, Total (columna 2), y las del exterior y el público con Sector Exterior (col. 11) y Sector Público (columna 12), respectivamente (dentro de "Banco de España. ACSB y contrapartidas"). Para los años 1982-92 se tomaron datos de los Boletines Estadísticos del Banco de España, correspondiendo las partidas de sector exterior, público y privado, respectivamente, a las partidas Sector Exterior (neto), Sector Público (Neto) y Sistema Crediticio. Neto. A partir de 1992 cambió la estructura de los Boletines Estadísticos del Banco de España y las partidas de los sectores exterior, público y privado pasaron a denominarse Sector Exterior (como diferencia entre Activos y Pasivos); Administraciones Públicas y Entidades de Crédito. Finalmente, los datos de la pignoración proceden de Martín Aceña (columna DISPUV o Dispuesto de Créditos con Garantía de Valores) ${ }^{16}$. Las cifras del redescuento especial proceden de las Series Históricas del Banco de España, concretamente en el renglón "Banco de España" - "Operaciones con el sistema bancario - Crédito dispuesto. Desglose" - columna 11 Redescuento Especial (Banca) ${ }^{17}$. Por último, los datos sobre saldo presupuestario y PIB provienen de reconstrucciones de Comín y Díaz y Carreras et al., respectivamente ${ }^{18}$.

\section{Presupuesto y dinero. Los canales de influencia}

El periodo de estudio comienza en 1874, como ya se dijo, con la concesión al Banco de España del monopolio de emisión de billetes ${ }^{19}$. Una concesión que, impulsada por las dificultades presupuestarias acumuladas entre 1868 y 1874 (el Sexenio Revolucionario), compensó el Banco concediendo al Tesoro un crédito y sendos anticipos sobre algunas figuras impositivas, acuerdo que se mantuvo cuando en 1874 se restauró la Monarquía Borbónica.

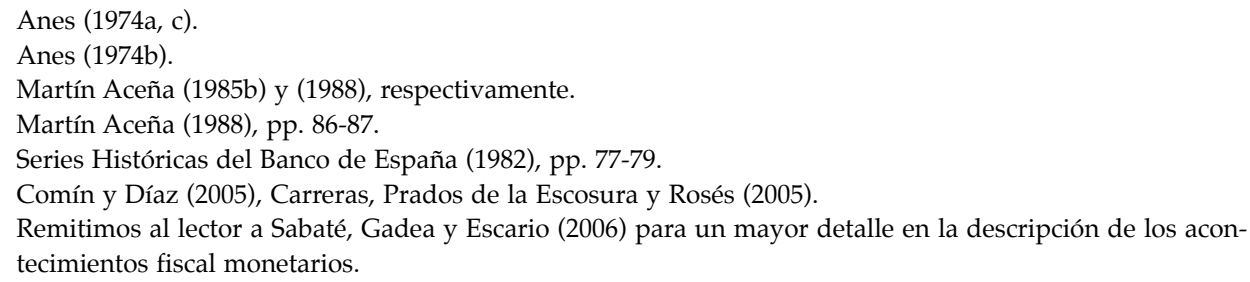


El Banco continuó apoyando financieramente el régimen alfonsino comprando títulos del Tesoro, que sucesivamente renovados, fueron acumulándose en el Banco hasta el comienzo de los ochenta, cuando se transformaron en deuda del Estado. Sin embargo, a mediados de los ochenta, la crisis agrícola española comenzó a afectar seriamente los ingresos impositivos, y la colocación de títulos del Tesoro en el Banco se reanudó, hasta representar más del $40 \%$ de la moneda de curso legal. En esta situación, en 1891, se renovó el monopolio del Banco de España, doblándole el límite de emisión. A cambio, el Banco garantizaba al Tesoro un nuevo crédito libre de intereses y acordó comprar deuda del Tesoro. Empezó entonces otro ciclo de renovaciones que culminaría con la colocación en el Banco de España de los llamados Pagarés de Ultramar, emitidos para sufragar el gasto extraordinario generado por la guerra en Cuba (1895-1898) y el conflicto derivado contra los Estados Unidos (1898).

El vínculo entre Tesoro y Banco encaja perfectamente con el relevante papel del sector público en la creación de base monetaria entre los años 1875-1898. Siguiendo las cifras del Cuadro 1a, se observa que para el conjunto del periodo al sector público le corresponden 3,47 puntos porcentuales sobre una tasa de crecimiento total de la base inferior, 2,98 puntos, por la mucho menor contribución de los componentes exterior y privado y la negativa del término residual "otros". El protagonismo del sector público es todavía más claro para el subperiodo 1896-1898, cuando su contribución a un crecimiento medio de la base del 16,05\% es del 17,28\%, frente al -1,45\% y $1,02 \%$ de los sectores privado y exterior, respectivamente.

CUADRO 1a

CONTRIBUCIONES SECTORIALES ABSOLUTAS AL CRECIMIENTO DE LA BASE MONETARIA 1875-1935

\begin{tabular}{rrrrrr}
\hline & c(exterior) & c(público) & c(privado) & c(otros) & tasa $\Delta \mathbf{B M}$ \\
\hline $\mathbf{1 8 7 5 - 1 9 3 5}$ & $\mathbf{1 , 1 3} \%$ & $\mathbf{0 , 6 6 \%}$ & $\mathbf{1 , 3 9 \%}$ & $-\mathbf{0 , 3 7 \%}$ & $\mathbf{2 , 8 1 \%}$ \\
& & $\mathbf{1 , 3 3 \%}$ & $\mathbf{0 , 7 2 \%}$ & & \\
$\mathbf{1 8 7 5 - 1 8 9 8}$ & $0,58 \%$ & $3,47 \%$ & $0,32 \%$ & $-1,38 \%$ & $2,98 \%$ \\
$\mathbf{1 8 7 5 - 1 8 9 5}$ & $0,52 \%$ & $1,50 \%$ & $0,57 \%$ & $-1,46 \%$ & $1,12 \%$ \\
$\mathbf{1 8 9 6 - 1 8 9 8}$ & $1,02 \%$ & $17,28 \%$ & $-1,45 \%$ & $-0,80 \%$ & $16,05 \%$ \\
$\mathbf{1 8 9 9 - 1 9 1 3}$ & $0,44 \%$ & $-3,37 \%$ & $2,07 \%$ & $0,71 \%$ & $-0,15 \%$ \\
$\mathbf{1 8 9 9 - 1 9 0 8}$ & $-0,35 \%$ & $-5,36 \%$ & $3,02 \%$ & $1,07 \%$ & $-1,62 \%$ \\
$\mathbf{1 9 0 9 - 1 9 1 3}$ & $2,02 \%$ & $0,62 \%$ & $0,16 \%$ & & $2,80 \%$ \\
$\mathbf{1 9 1 4 - 1 9 3 5}$ & $2,22 \%$ & $0,34 \%$ & $2,09 \%$ & & $4,65 \%$ \\
& & $2,20 \%$ & $0,23 \%$ & & \\
$\mathbf{1 9 1 4 - 1 9 1 9}$ & $7,76 \%$ & $0,21 \%$ & $3,78 \%$ & & $11,75 \%$ \\
& & $4,01 \%$ & $-0,02 \%$ & & $1,98 \%$ \\
$\mathbf{1 9 2 0 - 1 9 3 5}$ & $0,14 \%$ & $0,39 \%$ & $1,46 \%$ & & \\
& & $1,52 \%$ & $0,33 \%$ & & \\
\hline
\end{tabular}

Notas: Los porcentajes en cursiva que aparecen en determinados periodos son el resultado, entre 1917 y 1935 , de añadir la pignoración a la contribución del sector público y minorársela a la del privado.

Fuentes: Véase texto. 


\section{CUADRO 1b}

CONTRIBUCIONES SECTORIALES RELATIVAS AL CRECIMIENTO DE LA BASE MONETARIA 1875-1935

\begin{tabular}{rrrrrc}
\hline & cr(exterior) & cr(público) & cr(privado) & cr(otros) & tasa $\Delta \mathbf{B M}$ \\
\hline $\mathbf{1 8 7 5 - 1 9 3 5}$ & $\mathbf{4 0 , 3 3 \%}$ & $\mathbf{2 3 , 4 1 \%}$ & $\mathbf{4 9 , 3 1 \%}$ & $\mathbf{- 1 3 , 0 5 \%}$ & $\mathbf{1 0 0 \%}$ \\
& & $\mathbf{4 7 , 2 6 \%}$ & $\mathbf{2 5 , 4 6 \%}$ & & \\
$\mathbf{1 8 7 5 - 1 8 9 8}$ & $19,40 \%$ & $116,20 \%$ & $10,58 \%$ & $-46,18 \%$ & $100 \%$ \\
$\mathbf{1 8 7 5 - 1 8 9 5}$ & $46,16 \%$ & $133,68 \%$ & $50,86 \%$ & $-130,70 \%$ & $100 \%$ \\
$\mathbf{1 8 9 6 - 1 8 9 8}$ & $6,35 \%$ & $107,67 \%$ & $-9,06 \%$ & $-4,96 \%$ & $100 \%$ \\
$\mathbf{1 8 9 9 - 1 9 1 3}$ & $-298,66 \%$ & $2.286,00 \%$ & $-1.403,98 \%$ & $-483,36 \%$ & $100 \%$ \\
$\mathbf{1 8 9 9 - 1 9 0 8}$ & $21,58 \%$ & $330,26 \%$ & $-186,05 \%$ & $-65,80 \%$ & $100 \%$ \\
$\mathbf{1 9 0 9 - 1 9 1 3}$ & $72,05 \%$ & $22,09 \%$ & $5,86 \%$ & & $100 \%$ \\
$\mathbf{1 9 1 4 - 1 9 3 5}$ & $47,67 \%$ & $7,29 \%$ & $45,03 \%$ & & $100 \%$ \\
& & $47,34 \%$ & $4,99 \%$ & & $100 \%$ \\
$\mathbf{1 9 1 4 - 1 9 1 9}$ & $66,04 \%$ & $1,75 \%$ & $32,21 \%$ & & $100 \%$ \\
& & $34,14 \%$ & $-0,18 \%$ & & \\
$\mathbf{1 9 2 0 - 1 9 3 5}$ & $6,87 \%$ & $19,59 \%$ & $73,54 \%$ & & \\
& & $76,67 \%$ & $16,46 \%$ & & \\
\hline
\end{tabular}

Notas: Véanse Cuadro 1a y texto.

Estas cifras contrastan con las de la siguiente década, cuando de 1899 a 1908 (y también en 1911) el déficit desapareció del presupuesto español. Los orígenes de este cambio se encuentran en el saneamiento hacendístico de Fernández Villaverde, quien a través de la conversión de la deuda del Tesoro y el recorte de los intereses sobre los Pagarés de Ultramar, consiguieron controlar la carga financiera. Dio con ello comienzo una etapa de superávit presupuestarios que permitirían incluso amortizar parte de los pagarés colocados en el Banco. En esta misma línea, en 1902, se elevó la garantía en oro del billete, al objeto de ralentizar la expansión de crédito privado con la que el Banco había intentado inicialmente compensar la reducción de pagarés en su cartera. Y de hecho, la contabilización de las contribuciones sectoriales a la variación de la base monetaria confirma la narrativa. Tal como se refleja en el Cuadro 1a, fue el sector público el que dirigió la contracción monetaria. La base se redujo a una tasa media del $-0,15 \%$ entre 1899 y 1913 , a la que el componente público contribuyó con una participación negativa del -3,37\%, sobradamente capaz de compensar los impulsos positivos de los otros sectores. La contención tanto del crecimiento de la base, como del componente público en particular, se concentró sobre todo en los años 1899-1908 (-5,36\%), coincidiendo con los años de mayores superávit.

En claro contraste, durante la Gran Guerra, los déficit españoles empeoraron notablemente, fruto de una inestabilidad política que hizo imposible aprobar nuevos presupuestos de 1914 a 1921, en un contexto bélico que disparó los gastos. Sin embargo, incluso cuando volvió la normalidad, los impuestos fueron incapaces de 
cubrir la inversión en infraestructuras de los años veinte. El déficit tampoco desapareció con el advenimiento de la Segunda República en 1931, a pesar de las declaraciones del nuevo gobierno sobre su intención de equilibrar el presupuesto. Por ello, en este periodo, las necesidades financieras condujeron de nuevo al Tesoro hacia el Banco de España, aunque el procedimiento, toda vez que la Ley de 1902 había prohibido la colocación de bonos en el Banco de España, iba a ser distinto. Dicho procedimiento consistía en colocar deuda del Tesoro y del Estado en manos privadas, principalmente entre la banca, con la particularidad de que dicha deuda podía ser automáticamente pignorada en el Banco de España a un tipo de interés inferior al de su rendimiento. Así, desde 1917, los déficit no se monetizaban a través de la colocación de deuda en el Banco, sino mediante los créditos obtenidos por el sector privado a través de la pignoración. De modo que el nexo entre Tesoro y Banco se mantenía, con la única diferencia de que el nuevo mecanismo difuminaba la influencia del déficit sobre la base monetaria.

Y así se refleja en los datos de los Cuadros $1 \mathrm{a}$ y 1b, donde se observa, además, cómo la etapa 1914-1935 introdujo un nuevo protagonista en la evolución monetaria, el sector exterior. Durante los años de la Gran Guerra la balanza de pagos española se benefició de la neutralidad, aportando una expansión a la liquidez de 7,76 puntos (en términos relativos, más de las dos terceras partes de la expansión total de la base). Aunque a efectos de lo que aquí interesa, el dato más relevante es la confirmación de la aparente pérdida de protagonismo del sector público en la expansión monetaria. Así pues, entre 1914 y 1935, el sector público pasó a contribuir con tan sólo un $0,34 \%$ al crecimiento de la base, que fue del 4,65\% (un 7,29\% en términos relativos), contribución que se ve incluso más insignificante, con un $0,21 \%(1,75 \%$ relativizado), si nos centramos en los años de la I Guerra Mundial. Sin embargo, éste no es un descubrimiento inesperado teniendo en cuenta que por entonces las necesidades financieras del Tesoro fueron cubiertas preferentemente mediante la colocación de deuda entre suscriptores privados, luego pignorada en el Banco de España. En términos de la descomposición de la base monetaria, esto significa que el efecto de los déficit sobre el dinero estará registrado en el componente de créditos al sector privado.

De esta forma, aunque indirectamente, los déficit habrían influido sobre la base monetaria, pero no a través de la cartera de la autoridad monetaria, sino de la del sector privado. De manera más o menos diferida, dependiendo de las necesidades de liquidez de los prestatarios, la base aumentaría a medida que la banca ejercitara su derecho de pignorabilidad. El Estado conseguía así encubrir contablemente su responsabilidad en la expansión monetaria, aunque en la práctica, eran sus necesidades de financiación las que estaban detrás de la emisión de deuda y su pignoración. Que la pignoración hizo de la suscripción de deuda un negocio especialmente atractivo para la banca, lo demuestra el hecho de que a partir de entonces, la prin- 
cipal línea de crédito fuera la abierta con garantía de créditos y valores, en su gran mayoría títulos de deuda. De hecho, la contribución del sector privado como fuente de creación monetaria cae drásticamente (de una contribución del 2,09\% a otra del $0,23 \%$ sobre una tasa de crecimiento media de la base monetaria en 1914-1935 de $4,65 \%$ ) si no se considera dentro del componente privado el crédito obtenido a través de la pignoración de títulos de deuda. Por el contrario, si la pignoración se suma al componente público, la contribución pasa de $0,34 \%$ a un 2,20\% (en términos relativos, pasa de explicar del 7,29\% a un $47,34 \%$ del aumento de la base en esos años).

La Guerra Civil española conllevó un importante crecimiento en los medios de pago, que se duplicaron entre 1936 y $1942^{20}$. Aunque mayor trascendencia que el impacto extraordinario de la guerra sobre el ritmo de crecimiento del dinero, tuvieron otras decisiones tomadas en el mismo marco de reorganización monetaria, y que conllevaron la total eliminación de restricciones en el recurso del Tesoro al Banco de España y a la tenencia de títulos de deuda como contrapartida a la emisión de billetes $^{21}$. Aprovechando este margen, durante la Autarquía (periodo 1942-1959) la base monetaria se expandió a un ritmo muy superior al de las anteriores etapas, excepción hecha de los periodos bélicos ${ }^{22}$. Y aquí de nuevo veremos, en los Cuadros 2a y $2 b$, que parte sustancial de la expansión es atribuible a las necesidades de financiación pública ${ }^{23}$.

Cierto que el déficit, con máximos históricos en los cuarenta, parece trucarse en superávit en los cincuenta. Pero esto no debe inducir a engaño sobre la crónica insuficiencia del sistema impositivo de la época, rígido y altamente permisivo con el fraude. El espejismo radica en que los datos presupuestarios disponibles no incluyen las considerables necesidades de los Organismos Autónomos (OO.AA.), que se financiaron mediante deuda emitida bien por el Estado o bien por ellos mismos y que, cuando la preestabilización de 1957 limitó las posibilidades de emisión de deuda por cuenta del Estado, incrementaron espectacularmente la demanda directa de crédito al Banco de España ${ }^{24}$. La espectacularidad del incremento queda bien reflejada en el gráfico 2. El recurso directo de los OO.AA. al Banco de España excede al propio crecimiento de la base monetaria en 1958, dejando al descubierto la presión monetaria de las necesidades extrapresupuestarias del sector público en la época.

\footnotetext{
20 Véase Sardà (1970) y más recientemente, Sánchez Asiaín (1999, 2003).

21 Sobre los términos de la reorganización véase también Martín Aceña (1994).

22 Para la política monetaria desarrollada en la España autárquica, véase Sardà (1970) y González (1979). El Plan de Estabilización y Liberalización de 1959 es analizado en los escritos de Sardà recopilados por Ortega (1987a) y en Fuentes Quintana (1984). Véase además Barciela et al. (2001).

23 Véase Barciela et al. (2001), pp. 46-73.

24 González (1979), p. 59.
} 
CUADRO 2a

CONTRIBUCIONES SECTORIALES ABSOLUTAS AL CRECIMIENTO DE LA BASE MONETARIA 1942-1998

\begin{tabular}{rrrrrrr}
\hline & c(exterior) & c(público) & c(privado) & c(otros) & tasa $\Delta \mathbf{B M}$ & tasa $\Delta$ ALP \\
\hline $\mathbf{1 9 4 2 - 1 9 9 8}$ & $\mathbf{6 , 0 1} \%$ & $\mathbf{2 , 7 1} \%$ & $\mathbf{4 , 0 6 \%}$ & $-\mathbf{0 , 1 8} \%$ & $\mathbf{1 2 , 5 9 \%}$ & \\
& & $\mathbf{4 , 0 7 \%}$ & $\mathbf{3 , 2 4} \%$ & & & \\
$\mathbf{1 9 4 2 - 1 9 5 9}$ & $-0,36 \%$ & $3,34 \%$ & $7,88 \%$ & $-0,09 \%$ & $10,77 \%$ & \\
& & $7,14 \%$ & $4,09 \%$ & & & \\
$\mathbf{1 9 6 0 - 1 9 7 1}$ & $9,84 \%$ & $1,08 \%$ & $2,64 \%$ & $0,17 \%$ & $13,73 \%$ & \\
& & $1,82 \%$ & $1,91 \%$ & & & \\
$\mathbf{1 9 6 0 - 1 9 6 4}$ & $13,03 \%$ & $-1,16 \%$ & $-0,36 \%$ & $3,02 \%$ & $14,53 \%$ & \\
& & $-0,20 \%$ & $-1,31 \%$ & & & \\
$\mathbf{1 9 6 5 - 1 9 7 1}$ & $7,56 \%$ & $2,69 \%$ & $4,78 \%$ & $-1,87 \%$ & $13,16 \%$ & \\
& & $3,27 \%$ & $4,20 \%$ & & & \\
$\mathbf{1 9 7 2 - 1 9 8 3}$ & $7,47 \%$ & $14,41 \%$ & $-6,17 \%$ & $1,54 \%$ & $17,24 \%$ & \\
$\mathbf{1 9 7 2 - 1 9 7 7}$ & $5,98 \%$ & $2,97 \%$ & $5,66 \%$ & $2,78 \%$ & $17,38 \%$ & \\
$\mathbf{1 9 7 8 - 1 9 8 3}$ & $8,96 \%$ & $25,85 \%$ & $-18,01 \%$ & $0,30 \%$ & $17,09 \%$ & $13,51 \%$ \\
$\mathbf{1 9 8 4 - 1 9 9 1}$ & $12,42 \%$ & $-2,62 \%$ & $5,62 \%$ & $0,14 \%$ & $15,55 \%$ & $14,16 \%$ \\
$\mathbf{1 9 8 4 - 1 9 8 9}$ & $11,79 \%$ & $-4,56 \%$ & $15,14 \%$ & $0,16 \%$ & $22,52 \%$ & $11,54 \%$ \\
$\mathbf{1 9 9 0 - 1 9 9 1}$ & $14,31 \%$ & $3,20 \%$ & $-22,93 \%$ & $0,08 \%$ & $-5,34 \%$ & $6,31 \%$ \\
$\mathbf{1 9 9 2 - 1 9 9 8}$ & $5,98 \%$ & $-10,09 \%$ & $12,44 \%$ & $-4,34 \%$ & $3,99 \%$ & \\
\hline
\end{tabular}

Notas: Los porcentajes en cursiva que aparecen en determinados periodos son el resultado, entre 1942 y 1959 , de añadir la pignoración a la contribución del sector público y minorársela a la del privado. Entre 1962 y 1970 la cantidad que se añade o sustrae es la correspondiente al redescuento especial de efectos.

Fuentes: Véase texto.

\section{CUADRO 2b}

CONTRIBUCIONES SECTORIALES RELATIVAS AL CRECIMIENTO DE LA BASE MONETARIA 1942-1998

\begin{tabular}{rrrrrc}
\hline & cr(exterior) & cr(público) & cr(privado) & cr(otros) & tasa $\Delta \mathbf{B M}$ \\
\hline $\mathbf{1 9 4 2 - 1 9 9 8}$ & $\mathbf{4 7 , 7 0 \%}$ & $\mathbf{2 1 , 5 2 \%}$ & $\mathbf{3 2 , 2 5 \%}$ & $\mathbf{- 1 , 4 6 \%}$ & $\mathbf{1 0 0 \%}$ \\
& & $\mathbf{3 2 , 3 2 \%}$ & $\mathbf{2 5 , 7 2 \%}$ & & \\
$\mathbf{1 9 4 2 - 1 9 5 9}$ & $-3,35 \%$ & $31,03 \%$ & $73,16 \%$ & $-0,84 \%$ & $100 \%$ \\
& & $66,24 \%$ & $37,95 \%$ & & \\
$\mathbf{1 9 6 0 - 1 9 7 1}$ & $71,65 \%$ & $7,90 \%$ & $19,24 \%$ & $1,21 \%$ & $100 \%$ \\
& & $13,26 \%$ & $13,88 \%$ & & \\
$\mathbf{1 9 6 0 - 1 9 6 4}$ & $89,68 \%$ & $-7,99 \%$ & $-2,46 \%$ & $20,76 \%$ & $100 \%$ \\
& & $-1,40 \%$ & $-9,05 \%$ & & \\
$\mathbf{1 9 6 5 - 1 9 7 1}$ & $57,43 \%$ & $20,43 \%$ & $36,35 \%$ & $-14,22 \%$ & $100 \%$ \\
& & $24,83 \%$ & $31,96 \%$ & & \\
$\mathbf{1 9 7 2 - 1 9 8 3}$ & $43,32 \%$ & $83,59 \%$ & $-35,82 \%$ & $8,91 \%$ & $100 \%$ \\
$\mathbf{1 9 7 2 - 1 9 7 7}$ & $34,37 \%$ & $17,08 \%$ & $32,58 \%$ & $15,97 \%$ & $100 \%$ \\
$\mathbf{1 9 7 8 - 1 9 8 3}$ & $52,43 \%$ & $151,24 \%$ & $-105,40 \%$ & $1,73 \%$ & $100 \%$ \\
$\mathbf{1 9 8 4 - 1 9 9 1}$ & $79,85 \%$ & $-16,87 \%$ & $36,14 \%$ & $0,88 \%$ & $100 \%$ \\
$\mathbf{1 9 8 4 - 1 9 8 9}$ & $52,35 \%$ & $-20,27 \%$ & $67,22 \%$ & $0,69 \%$ & $100 \%$ \\
$\mathbf{1 9 9 0 - 1 9 9 1}$ & $-268,22 \%$ & $-59,89 \%$ & $429,70 \%$ & $-1,58 \%$ & $100 \%$ \\
$\mathbf{1 9 9 2 - 1 9 9 8}$ & $149,91 \%$ & $-252,68 \%$ & $311,50 \%$ & $-108,72 \%$ & $100 \%$ \\
\hline
\end{tabular}

Notas: Véanse Cuadro 2a y texto. 


\section{GRÁFICO 2}

VOLUMEN DEL SALDO OFICIAL, CRECIMIENTO DE LA BASE MONETARIA Y RECURSO DIRECTO AL BANCO DE ESPAÑA DE LOS OO.AA.

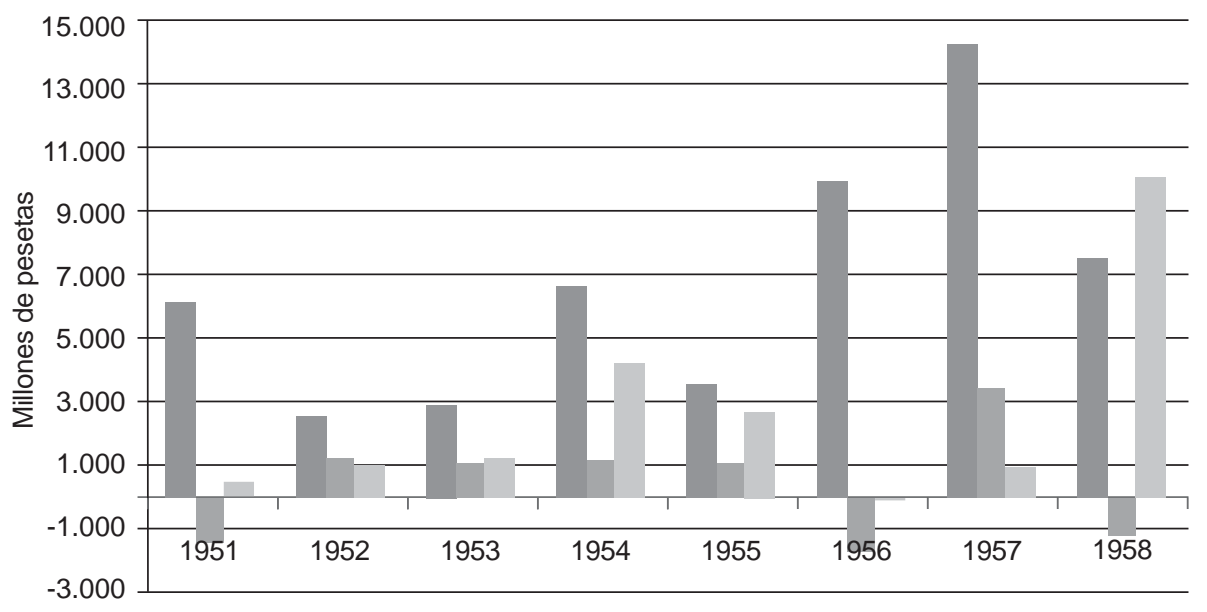

Incremento de la base monetaria Saldo presupuestario oficial Recurso directo OO.AA

Fuentes: Saldo presupuestario e incremento de la base, véase Sección 2. Los créditos personales del Banco de España a los OO.AA. en: Banco de España, "La situación monetaria y financiera", Madrid, 1959.

En cualquier caso, el punto aquí relevante es que las necesidades de financiación pública (presupuestarias o extrapresupuestarias) durante la autarquía, se encauzaron preferentemente a través de la emisión de deuda pignorable. La celeridad con la que habitualmente se pignoraban los títulos hizo nuevamente de este tipo de deuda un potente instrumento de creación de liquidez, que sumado al recurso directo al Banco de España, impulsó la expansión monetaria española en la autarquía ${ }^{25}$. Así, la contribución pública al crecimiento de la base monetaria entre 1942 y 1959, ya relevante en sí misma (3,34\% sobre el 10,77\% que aumenta la base monetaria), se eleva notablemente, pasando a 7,14 puntos (esto es, pasando de explicar el 31 al 66\% del crecimiento de la base en términos relativos), si trabajamos con el componente público ampliado. Por otro lado, destaca la contribución ligeramente negativa del sector exterior, hecho que encaja perfectamente con el calificativo autárquico del periodo, y que contrasta claramente con lo ocurrido en la siguiente década, durante la cual, la economía española inicia un periodo de fuerte crecimiento, en un contexto de aperturismo y la consiguiente acumulación de reservas.

25 Como explica Poveda (1972), p. 173, los valores se pignoraban inmediatamente por el 90 por 100 del nominal al mismo tipo de interés, con lo cual los bancos sólo comprometían un 10 por 100 del capital tomado. 
En términos generales, durante los años sesenta, el sector exterior explica un significativo $9,84 \%$ de un crecimiento medio de la base del 13,73\%, es decir, casi las tres cuartas partes del crecimiento total. El sector exterior fue por tanto el factor protagonista en la generación básica de liquidez, muy destacadamente hasta 1964. Entretanto, la contribución del sector público resulta mucho más modesta, con un porcentaje del 1,08\% en 1960-1971.

Con respecto al sector público, hay que decir que la regulación por el DecretoLey de 7 de junio de 1962, de Nacionalización y Reorganización del Banco de España, mantuvo abiertas las posibilidades para una financiación monetaria ${ }^{26}$. Sin embargo, estas posibilidades no fueron aprovechadas hasta que se agotaron los efectos estabilizadores de 1959 y, a mediados de los sesenta, reaparece el déficit. Entonces el Estado, pero también los Organismos Autónomos (cuyo déficit, recuérdese, no está recogido en la cifra oficial) recurren de nuevo al Banco ${ }^{27}$. Además, hay que contar con las interferencias del sector público en el sector privado canalizadas a través del redescuento especial.

Desde mediados de los sesenta hasta 1970, el redescuento especial, esto es, el redescuento automático en el Banco de España de aquellos efectos que canalizaban financiación barata hacia los sectores considerados por el gobierno de desarrollo prioritario, se constituyeron en la principal fuente de liquidez privada. Los sectores prioritarios eran autorizados a emitir y colocar efectos en la banca privada, de forma que si la banca deseaba recuperar su liquidez antes del vencimiento de los activos, el Banco de España respondía por ellos, redescontándoselos a una tasa inferior a la del descuento. La banca financiadora se aseguraba así mediante el redescuento automático (con un procedimiento de fuerte semejanza con la pignoración), una fuente de liquidez remunerada ${ }^{28}$. Una posibilidad que adquirió en la segunda mitad de la década un claro impulso, conforme ilustra el gráfico 3. De este modo, procediendo como hacíamos con la deuda pignorable, si asignamos al sector público la liquidez obtenida vía redescuento especial, su contribución pasa de explicar un 2,69\% al

26 El artículo 20 de la Ley proponía un límite al recurso al Tesoro sin devengo de interés. Sin embargo, el límite resultaba más que difuso al no concretarse, por ejemplo, qué activos del Banco sobre el Tesoro podían considerarse anticipos o cuál era la base de cálculo (seguían sin ser públicos los presupuestos de los Organismos Autónomos). Véase Poveda (1972), pp. 133-134.

$27 \quad$ En este punto, cabe destacar el apoyo del Banco de España a distintos organismos agrícolas oficiales, como por ejemplo el Servicio Nacional del Trigo, la Comisaría de Abastecimientos y Transportes o la Comisión de Compras de Excedentes de Vino. Entre 1966 y 1969 aumentó constantemente el crédito del Banco a estos organismos; situación que no mejoró con la creación en ese último año del F.O.R.P.P.A. (Fondo de Ordenación y Regulación de Producciones y Precios Agrarios), puesto que a este nuevo organismo le fueron transferidos la mayor parte de los créditos y operaciones de sus predecesores. Poveda (1972), pp. 153-156 y (1980), p. 130.

28 Según Poveda (1972), p. 184, el éxito del redescuento radicó en que, como en la pignoración, “la Banca no compromete recursos propios en las operaciones, sino que se limita a actuar de intermediario entre el cliente y el Banco de España, ganando con ello el margen entre el tipo de descuento y el de redescuento, amén de las comisiones bancarias". En 1970, sólo el 25\% de los efectos no estaban redescontados. 
$3,27 \%$ sobre un crecimiento de la base del $13,16 \%$ en $1965-1971^{29}$. En términos relativos, la imputación del redescuento especial al sector público haría que éste pasara de explicar un $20,43 \%$ al $24,83 \%$ de crecimiento de la base ${ }^{30}$. En cualquier caso, ambos porcentajes fueron suficientes para que la literatura continuara asignando a los sesenta el calificativo de años de acomodación monetaria, en contraste con la voluntad de intervención reconocida a los primeros setenta ${ }^{31}$.

Reflejo de la nueva voluntad interventora, se imponen a principios de los 70 sendos coeficientes de caja a la banca primero, en 1970, y a las cajas de ahorro luego, en 1971. Este último año, además, se sustituye el redescuento especial por el llamado coeficiente de inversión obligatorio, cerrando definitivamente la puerta de acceso automático de la banca al crédito del Banco de España ${ }^{32}$. Finalmente, en 1973, el Banco de España empieza a aplicar una estrategia de control monetario en dos niveles. La contención de la inflación se concreta en el control estricto de una variable intermedia (agregado monetario Disponibilidades Líquidas, M3) a través de una variable instrumental (los Activos de Caja del Sistema Bancario o ACSB) ${ }^{33}$. Para hacer operativa la variable ACSB se pusieron en marcha la subasta de bonos del Banco y los préstamos de regulación como herramientas básicas para obtener un sistema continuo de intervención en los incipientes mercados interbancarios ${ }^{34}$.

Todo esto, sin embargo, no implicó una moderación de las tasas de crecimiento monetario. En el periodo 1972-1983, la base monetaria aumentó a un promedio anual del $17,24 \%$, claramente superior al de la década precedente, en que había promediado un 13,73\%. Especialmente llamativo fue el ritmo de crecimiento de la contribución del sector público entre 1978 y 1983, recuperando en esos años su protagonismo como principal impulsor de la expansión de la liquidez. Este sector contribuye entonces con un 25,85\% al 17,09\% de incremento de la base, compensando sobradamente la presión a la baja $(-18,01 \%)$ de un sector privado afectado por el impacto de la crisis económica.

29 Si al efecto redescuento se le suma el de pignoración de los títulos de deuda aún en manos de la banca, el cambio en las contribuciones resulta incluso mayor. En tal caso, el sector público pasaría de explicar un $2,69 \%$ al 5,36\% sobre un crecimiento de la base del 13,16\%.

30 Puede ser discutible sustraer la liquidez generada por redescuento especial del crédito al sector privado si se argumenta que estos efectos eran creados para la financiación de entes privados (los sectores 'prioritarios') y redescontados por iniciativa de la banca privada. Sin embargo, lo que aquí se plantea es que de no ser por la decidida actuación intervencionista del sector público (que en su papel de promotor de desarrollo privilegiaba ciertos sectores), la banca hubiera ofrecido unas condiciones de préstamo más duras, y los sectores favorecidos se habrían mostrado con toda seguridad más reacios al endeudamiento.

31 Poveda (1972), pp. 269-270, juzga que esa acomodación se refleja tanto en ampliación de la base monetaria por recurso directo del sector público al Banco como por la línea de crédito del redescuento del instituto emisor a la banca. Rojo y Pérez (1977) y Martínez Méndez (1981) refrendan esta idea de acomodación monetaria pasiva, por contraposición a la voluntad de intervención sistemática que aflora a principios de los setenta.

32 Véase Poveda (1980) p. 120.

33 Para una descripción exhaustiva y la valoración del cambio, véase Rojo y Pérez (1977).

34 Como se explica en Aríztegui (1988), p. 910. 
GRÁFICO 3

EVOLUCIÓN DEL DESCUENTO AUTOMÁTICO DE EFECTOS POR LA BANCA PRIVADA, 1903-1981

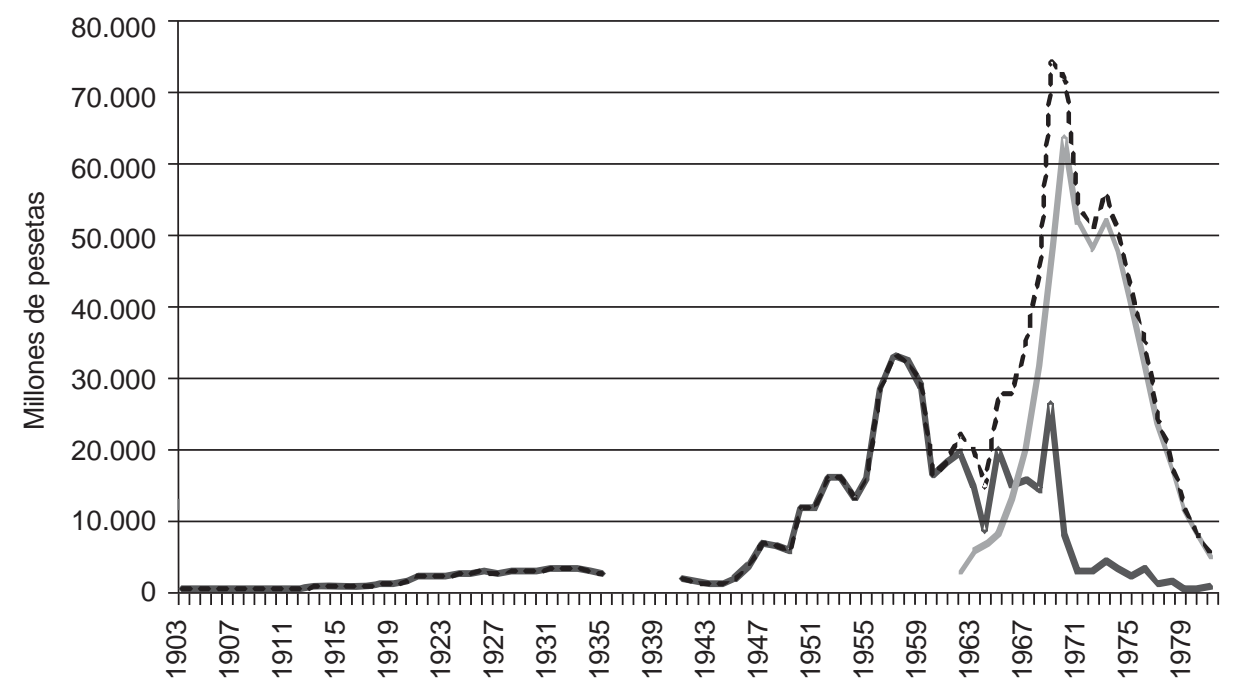

- Deuda pignorada — Redescuento especial - -- deuda pignorada + redescuento especial

Fuentes: Véase Sección 2.

La alta contribución que alcanzó el sector público durante los años 1978-1983, la mayor de todo el periodo, fue consecuencia de la explosión de gasto que conllevó, tras el 77, el proceso de creación del Estado de Bienestar en un contexto de pronunciada crisis económica ${ }^{35}$. Los déficit se financiaron fundamentalmente a través del crédito del Banco de España a las Administraciones Públicas, que de representar un 26\% del total de los activos del Banco en 1977 alcanzan un 55\% en $1982^{36}$.

35 Una narración detallada del tratamiento de la crisis económica española implementado en los Pactos de la Moncloa de 1977 puede leerse en Fuentes Quintana (2004). Una visión de las políticas monetarias instrumentadas desde la Constitución de 1978 hasta el ingreso de España en la UME en 1998, y su relación con las presupuestarias, en Malo de Molina (2003).

36 Domínguez Martínez (1990) destaca que en los años 1979-1980, el gran incremento del déficit y la ausencia de otras vías de financiación hicieron que el recurso del Estado al Banco de España superase por vez primera el límite del 12\% establecido en la Ley de Nacionalización y Reorganización del Banco de España de 1962 y mantenido en la Ley General Presupuestaria de 1977. A pesar de que la Ley de PGE para 1980 insistía en la vigencia de este límite, la Ley de PGE para 1981 terminó transformando los anticipos concedidos hasta final de ejercicio en créditos (sin interés) no computables como anticipos, y en consecuencia, no computables en el límite. Sucesivas leyes (PGEs de 1981 a 1986) siguieron transformando el porcentaje que superaba el $12 \%$ en este tipo de créditos, a costa de desvirtuar el concepto inicial de anticipos. Esto contribuyó a que, según Ortega (1987b), entre 1977 y 1982, el recurso al Banco de España financiara más de tres cuartas partes del déficit. En la misma línea, en un trabajo anterior Ortega (1984) ya había señalado que entre 1978 y 1982 se monetizó el 85\% del déficit. 
En 1983 el recurso directo al Banco cede protagonismo a la colocación de pagarés en su activo, y a partir de 1984, con el objetivo explícito de frenar la expansión del dinero de alto contenido, el grueso de la financiación pública pasa a obtenerse de la colocación de deuda en el mercado. Este cambio en el proceso de financiación explicaría el fin de las contribuciones públicas al crecimiento de la base monetaria en el resto del periodo, tal y como reflejan nuestros cálculos, hasta la entrada de España en la UEM.

Así, en la etapa 1984-1991, el crecimiento de la base estuvo liderado por el sector exterior. Su fuerte contribución al crecimiento de la base monetaria (12,42\% sobre un total de 15,55\%), deja bien patente el proceso de integración financiera que vivió la economía española tras su ingreso en la entonces todavía Comunidad Económica Europea. Aunque más llamativo que el incremento de la contribución del componente exterior es el descenso del peso del sector público en 1984-1991 como factor de creación de base monetaria, que pasa a ser negativo (-2,62\%). Este descenso en su participación, como se anticipaba, fue debido a que el Estado comenzó, a partir de 1984, a financiar gran parte de su déficit por emisión de títulos colocados en el mercado. Con ello no quiere decirse que el déficit dejara, por este motivo, de tener un reflejo monetario. Digamos que la sombra monetaria del déficit deja entonces de proyectarse sobre la base monetaria para proyectarse sobre los Activos Líquidos en manos del Público (ALP), desde 1984, el nuevo agregado de control monetario en España.

La expansión de los ALP (M3 más Otros Activos Líquidos en manos del público, OAL), no puede desligarse de la proliferación de títulos públicos que, emitidos a muy corto plazo (pagarés y letras), aportan el grueso de la financiación del déficit hasta $1990^{37}$. El Cuadro 3 pone de manifiesto la relevante participación de las emisiones de esos títulos en la proliferación de OAL y, por esta vía, en la expansión de los ALP. Entre 1984 y 1989, la emisión de pagarés y letras supuso casi el 25\% del crecimiento total de los ALP, contribución que llegó a alcanzar más del $54 \%$ en el año 86. La clave, por tanto, está en que el déficit no se financió "con el ahorro estable del público" sino, en una parte relevante, en los mercados monetarios; además de que la banca, mediante la cesión temporal al sector privado, hizo líquida la emisión de una parte de la deuda a medio y largo plazo. De este modo, aunque los títulos públicos no se colocaban en la cartera del banco y no ampliaban la base monetaria, seguían interfiriendo en el control monetario ${ }^{38}$. De hecho, esta interferencia se pondría pronto de manifiesto tras el ingreso de la peseta en el Sistema Monetario Europeo (SME).

\footnotetext{
37 El calendario de medidas adoptadas durante 1983 y 1984 en Aríztegui (1990). Véase también Banco de España (1983), Informe Anual. Una evolución detallada de las masivas reformas de los coeficientes de caja e inversión obligatoria en Repullo (1990).

38 Marín y Peñalosa (1997), p. 208.
} 


\section{CUADRO 3}

RELEVANCIA DE PAGARÉS Y LETRAS EN EL CRECIMIENTO DE OAL Y ALP: CONTRIBUCIONES ABSOLUTAS Y RELATIVAS

\begin{tabular}{crrrrr}
\hline & Pagarés & Letras & $\begin{array}{c}\mathbf{c}(\mathbf{p}+\mathbf{l}) \text { al } \\
\mathbf{c r e c i m i e n t o} \\
\text { OAL }\end{array}$ & $\begin{array}{c}\mathbf{c}(\mathbf{p}+\mathbf{l}) \text { al } \\
\mathbf{c r e c i m i e n t o} \\
\text { ALP }\end{array}$ & $\begin{array}{c}\text { cr(p+l) al } \\
\text { crecimiento } \\
\text { ALP }\end{array}$ \\
\hline $\mathbf{1 9 8 2}$ & 24.100 & & $11,61 \%$ & $0,15 \%$ & $0,89 \%$ \\
$\mathbf{1 9 8 3}$ & 291.900 & & $54,57 \%$ & $1,50 \%$ & $9,77 \%$ \\
$\mathbf{1 9 8 4}$ & 703.200 & & $55,54 \%$ & $2,00 \%$ & $13,34 \%$ \\
$\mathbf{1 9 8 5}$ & 1.443 .300 & & $90,54 \%$ & $3,13 \%$ & $23,76 \%$ \\
$\mathbf{1 9 8 6}$ & 3.404 .100 & & $166,80 \%$ & $7,33 \%$ & $54,29 \%$ \\
$\mathbf{1 9 8 7}$ & 3.447 .400 & 566.900 & $31,07 \%$ & $2,01 \%$ & $13,46 \%$ \\
$\mathbf{1 9 8 8}$ & 2.717 .700 & 2.378 .900 & $35,60 \%$ & $3,10 \%$ & $23,10 \%$ \\
$\mathbf{1 9 8 9}$ & 2.522 .200 & 3.851 .700 & $35,80 \%$ & $3,23 \%$ & $21,69 \%$ \\
$\mathbf{1 9 9 0}$ & 2.010 .300 & 5.348 .600 & $322,82 \%$ & $2,17 \%$ & $18,44 \%$ \\
\hline $\mathbf{1 9 8 4 - 1 9 8 9}$ & & & $69,22 \%$ & $3,47 \%$ & $24,94 \%$ \\
$\mathbf{1 9 8 2 - 1 9 9 0}$ & & & $56,04 \%$ & $2,74 \%$ & $19,86 \%$ \\
\hline
\end{tabular}

Notas: Columnas (1) y (2): cifras absolutas en millones de pesetas. Columnas (3) y (4): contribuciones absolutas de Pagarés y Letras al crecimiento de los agregados monetarios OAL y ALP, calculadas como $c(X)_{t}=\left(X_{t}-X_{t-1}\right) / Y_{t-1}$, siendo $X=$ Pagarés+Letras, e $Y=O A L$ y ALP, respectivamente. Columna (5) contribución relativa al crecimiento del agregado ALP. En este caso se dividen las absolutas por la correspondiente tasa de crecimiento del agregado $\left(Y_{t}-Y_{t-1}\right) / Y_{t-1}$.

Fuentes: Boletines Estadísticos del Banco de España. A partir de 1992 cambia su estructura y ya no se ofrece el desglose de las cifras de pagarés y letras.

El ingreso en el SME en junio de 1989 conllevó un cambio en la estrategia de control monetario. El compromiso asumido (la cotización de la peseta podía fluctuar un $\pm 6 \%$ sobre la paridad central de 65 pesetas frente al marco alemán), supeditaba la evolución de las variables monetarias a la determinación de un tipo de interés compatible con la permanencia de la peseta dentro de la banda. De este modo, el objetivo monetario en forma de crecimiento de la cantidad de dinero se vio desplazado por el objetivo cambiario, y en lugar de los activos de caja, el tipo de interés a corto plazo (desde 1990 determinado exclusivamente a través de intervenciones de mercado abierto) se erigió en variable operativa única. Sin embargo, dicha estrategia tuvo que mantenerse inicialmente en suspenso por la falta de colaboración del presupuesto que, con sus efectos expansivos sobre la liquidez, a fin de mantener la inflación relativamente controlada, exigía aplicar unos tipos de interés excesivamente altos $^{39}$. Por esta razón, hasta enero de 1991, las tensiones de apreciación inducidas por esos altos tipos hubieron de contenerse vía control de cambios.

39 Véase Ayuso y Escrivá (1997), p. 103. 
En la práctica, la batalla a esta inconsistencia de políticas (política fiscal expansiva versus política monetaria restrictiva) no se vencería hasta que, tras la crisis del SME abierta por el no danés a Maastricht, se afianzase en España la voluntad de acceder a la Unión Monetaria. En este contexto, el Banco de España inauguró su autonomía (Ley de 1 de junio de 1994) aplicando, desde enero de 1995, una estrategia de control directo sobre la inflación. El Banco anunció como objetivo una tasa de inflación del 3\% (IPC) para 1997, que llevada a 1995, implicaba cerrar el ejercicio con una tasa entre el 3,5 y el 4\%. Este mismo año, para cumplir su propósito, ante cierto revival de aceleración inflacionista, no dudó en interrumpir el recorte de intereses con que se venía apoyando la salida de la crisis económica de 1992-93. La corrección lograda, perceptible ya en la segunda mitad del año, confirmó su determinación antiinflacionista, fruto de la cual se cumplió el requisito de conseguir un diferencial de menos de 1,5 puntos porcentuales sobre la media de los tres países menos inflacionistas. Un logro, en cualquier caso, que no se hubiera conseguido sin el simultáneo alivio de las presiones de financiación pública sobre la creación de dinero. La contribución del sector público al crecimiento de la base es de nuevo negativa $(-10,09 \%)$ para el periodo $1992-1998$ y, además, pierden impulso las emisiones de deuda a corto a partir de 1996, cuando el déficit experimenta un profundo recorte ${ }^{40}$.

\section{Presupuesto y dinero. La relación}

La historiografía y los cálculos de las secciones anteriores sugieren que la necesidad de financiar el déficit condicionó de forma sostenida la creación de dinero en la España de la peseta. Bien fuere a través de la creación de dinero base, con monetización directa o indirecta, o bien a través de la emisión de títulos líquidos, surge la idea de que los recurrentes desequilibrios presupuestarios proyectaron una larga sombra monetaria hasta la integración en la UEM. El objetivo de esta sección es ilustrar dinámicamente la existencia de una conexión causal entre el saldo presupuestario y diferentes variables monetarias, primero con la base monetaria y posteriormente con los ALP.

En cuanto a las propiedades de las variables, los resultados de aplicar tests de raíces unitarias y estacionariedad (Cuadro 4) confirman que las series saldo presupuestario relativizado por el PIB nominal $(b)$ y variación de la base monetaria $(d m b)$

40 Con respecto a la contribución negativa del sector público al crecimiento de la base, téngase en cuenta que el recurso al Banco de España fue limitado a partir de 1990 al nivel alcanzado a 31 de diciembre de 1989, y definitivamente prohibido con la Ley de Autonomía del Banco de España. Véase Marín y Peñalosa (1997), p. 215 y Carreras y Tafunell (2004), pp. 419 y 422. Sobre la trascendencia del recorte del déficit, véase Malo de Molina (2003). 
son $\mathrm{I}(0)$, por lo que se puede aplicar un modelo VAR estacionario para estudiar su relación. A su vez, la variación del agregado monetario ALP $(d m)$, genera algunas dudas sobre su verdadero orden de integración debido a que, si bien los test la señalan como serie estacionaria con tendencia determinística, no ofrecen un resultado concluyente en el modelo con término independiente y sin tendencia. Por dicho motivo, en el contraste de la relación entre presupuesto y ALP se aplica la metodología de Pesaran et al. ${ }^{41}$.

\section{CUADRO 4}

CONTRASTES DE RAÍZ UNITARIA Y TEST DE ESTACIONARIEDAD

\begin{tabular}{lllll}
\hline & ADF & PP & MZ - GLS & KPSS \\
\hline Con constante y tendencia & $-5.48^{\star \star}$ & $-9.24^{\star \star}$ & $-4.29^{\star \star}$ & 0.11 \\
dmb & $-5.58^{\star \star}$ & $-5.48^{\star \star}$ & $-4.37^{\star \star}$ & 0.13 \\
dm & -3.22 & $-4.05^{\star \star}$ & $-3.29^{\star}$ & 0.07 \\
b & & & $-3.26^{\star \star}$ & $0.59^{\star}$ \\
\hline Con constante & $-5.13^{\star \star}$ & $-8.83^{\star \star}$ & $-2.45^{\star}$ & $0.97^{\star \star}$ \\
dmb & $-3.09^{\star}$ & $-4.24^{\star \star}$ & $-3.11^{\star \star}$ & 0.33 \\
dm & $-3.05^{\star}$ & $-3.67^{\star \star}$ & & \\
b & & & &
\end{tabular}

* Significativa al 5\%. Los valores críticos de los test ADF y PP se encuentran en McKinnon (1996). El número de retardos del test ADF se ha seleccionado según la metodología de Ng y Perron (1995), y el del test MZt-GLS según el criterio de SBIC. En los test PP y KPSS la ventana de Bartlett se ha utilizado como un estimador kernel, eligiendo la amplitud de banda según la metodología de Newey y West (1994).

** Significativa al nivel de confianza del $1 \%$.

Empezando con el análisis de la relación entre saldo y base monetaria, se lleva a cabo el análisis de causalidad de Granger a partir de un modelo de Vectores Autorregresivos $(\mathrm{VAR})^{42}$. De forma general, un VAR de orden $p$ se puede expresar como:

$$
Y_{t}=\sum_{i=1}^{p} \gamma_{i} Y_{t-i}+\alpha D_{t}+\varepsilon_{t}
$$

donde $Y_{t}$ es un vector de $k$ variables endógenas en el que $D_{t}$ incluye los componentes determinísticos, esto es, el término independiente, la tendencia y las variables dummy. En el caso que aquí se presenta, el modelo VAR es bivariante $(k=2)$ y se utiliza la siguiente especificación:

\footnotetext{
41 Pesaran, Shin y Smith (2001).

42 Granger $(1969,1988)$.
} 


$$
\begin{aligned}
& Y_{1 t}=\sum_{i=1}^{p} \gamma_{i} Y_{1 t-i}+\sum_{i=1}^{p} \mu_{i} Y_{2 t-i}+\alpha D_{t}+\varepsilon_{t} \\
& Y_{2 t}=\sum_{i=1}^{p} \lambda_{i} Y_{1 t-i}+\sum_{i=1}^{p} \delta_{i} Y_{1 t-i}+\beta D_{t}+\xi_{t}
\end{aligned}
$$

En el contexto de este modelo, la hipótesis nula de no-causalidad en el sentido de Granger se contrasta mediante la aplicación del test de ratio de verosimilitud (LR), haciendo $\mu_{i}=0 \forall i$ en [2], y $\delta_{i}=0 \forall i$ en [3] una vez confirmada la correcta especificación del modelo y seleccionado el orden del VAR.

Evidentemente, en este caso $Y_{1}$ e $Y_{2}$ se concretan en las variables saldo presupuestario $b$ y variación de la base monetaria $d m b$, con lo que los $p$-values del Cuadro 5 informan del nivel de confianza al que se puede rechazar la hipótesis nula de no-causalidad. Así pues, los resultados obtenidos con las series que cubren todo el periodo 1874-1998 muestran una fuerte causalidad en el sentido de Granger (a un nivel de confianza del 1\%) del saldo presupuestario sobre las variaciones en la base monetaria $^{43}$. Por otro lado, no se detecta que haya habido causalidad desde los cambios en la base hacia el presupuesto ${ }^{44}$. Además, prueba de que las injerencias monetarias del sector público no se limitaron a las presupuestarias, hallamos que la relación de causalidad se hace más intensa cuando minoramos el crecimiento de la base monetaria por el importe del recurso directo de los OO.AA. al Banco de España $\left(d m b^{*}\right)^{45}$.

Introducido este matiz, y volviendo a la relación entre déficit presupuestario y base monetaria, el siguiente paso consistió en confirmar el cambio de política de financiación a partir de 1983. Con tal fin se replicó la estimación para distintos cortes temporales y los resultados obtenidos se ofrecen en el Cuadro 6. De acuerdo con ellos, el debilitamiento de la causalidad cuando el período se amplía ligeramente de

43 El parámetro de largo plazo de la relación entre saldo e incremento de base resulta negativo y muy significativo.

Las series españolas de saldo presupuestario requieren la inclusión en el modelo de tres variables dummy. La primera toma valor 1 durante los años de las guerras cubano-estadounidenses (dCuba 1896-1898) -0 para el resto- con el fin de cubrir la ignorancia de las cifras del déficit real durante este periodo. En segundo lugar, las dummies dMor1 y dMor2 toman valor 1 en los años 1909-1911 y 1921-1922, respectivamente; años en que tuvieron lugar los conflictos con Marruecos, originando fluctuaciones atípicas en las cifras del déficit. Por último, se incluye también la dummy $d 90$ (con valor 1 para el año 1990 y 0 para el resto) para evitar la distorsión que generaría el outlier de ese año en la serie $d m b$ (cae drásticamente debido a las limitaciones impuestas al crédito al sector privado).

$44 \quad$ El sentido de la causalidad de la base monetaria hacia el saldo presupuestario se corrobora gráficamente mediante el estudio de la descomposición de la varianza del error de predicción (FEVD) y de las funciones impulso-respuesta (IRF) [véase Lütkepohl (1991)], no incluido por razones de espacio.

45 Dada la ausencia de registro de los déficit de los OO.AA., esta es la única opción factible de aproximar su efecto distorsionador sobre la relación entre necesidades públicas de financiación y base monetaria. 
1874-1984 a 1874-1991, casa perfectamente con la decisión de pasar entonces a una financiación ortodoxa del déficit, en que el recurso al Banco de España se sustituye por emisión de títulos. Por su parte, la voluntad española de cumplir los requisitos de convergencia de Maastricht en materia de inflación, podría explicar el debilitamiento final del nexo entre saldo y base monetaria que se aprecia al ampliar el análisis al período completo 1874-1998. Las trabas legales al seigniorage (prohibición total a los bancos centrales de concesión de crédito al sector público para acceder a la II Fase de la UEM, en 1 enero 1994) sumadas al fuerte avance en el control del déficit en los últimos años, encajarían con el debilitamiento que entonces experimenta el vínculo.

\section{CUADRO 5}

RELACIONES DE CAUSALIDAD Y CORRELACIÓN CONTEMPORÁNEA ENTRE SALDO PRESUPUESTARIO Y VARIACIÓN DE BASE MONETARIA

\begin{tabular}{ccc}
\hline & $b_{t-1} \rightarrow d m b_{t}$ & $b_{t-1} \rightarrow d m b_{t}^{*}$ \\
Causalidad & 12,34 & 13,24 \\
$\mathbf{1 8 7 4 - 1 9 9 8}$ & $(0,000)$ & $(0,000)$ \\
& $d m b_{t-1} \rightarrow b_{t}$ & $d m b_{t-1}^{*} \rightarrow b_{t}$ \\
& 1,18 & 0,89 \\
& $(0,278)$ & $(0,345)$ \\
\hline
\end{tabular}

Notas: El Cuadro muestra el test LR de causalidad en el sentido de Granger; entre paréntesis el $p$-value. El número de retardos de los modelos VAR (1) se ha seleccionado de acuerdo con los criterios SBIC y AIC. Se contrastan además autocorrelaciones, heteroscedasticidad y normalidad en los residuos. La exclusión de las 4 dummies del modelo ha sido contrastada mediante el test LR.

Fuentes: Saldo presupuestario e incremento de la base, véase Sección 2. Los créditos personales del Banco de España a los OO.AA. en: Banco de España, "La situación monetaria y financiera", Madrid, 1959. Restándolos de la base monetaria se ha construido la serie $d m b^{\star}$ (incremento relativizado por el PIB).

\section{CUADRO 6}

ESTIMACIÓN RECURSIVA DE LA CAUSALIDAD DEL SALDO PRESUPUESTARIO HACIA LA VARIACIÓN DE LA BASE MONETARIA

\begin{tabular}{ccc}
\hline Causalidad: $\boldsymbol{b}_{\boldsymbol{t}-\mathbf{1}} \rightarrow \boldsymbol{d m b}_{\boldsymbol{t}}$ & LR-test & $p$-value \\
\hline $\mathbf{1 8 7 4 - 1 9 8 4}$ & 15,14 & $(0,000)$ \\
$\mathbf{1 8 7 4 - 1 9 9 1}$ & 13,19 & $(0,000)$ \\
$\mathbf{1 8 7 4 - 1 9 9 8}$ & 9,77 & $(0,002)$ \\
\hline
\end{tabular}

Notas: Ver Cuadro 5 y nota al pie 28.

En este cuadro se ha omitido la variable dummy $d 90$, dado que en un procedimiento como el recursivo podría producir un impacto excesivo sobre los resultados. Por ello el test LR para el año 1998 no coincide con el que ilustra la causalidad de $b$ sobre $d m b$ para el periodo completo en el Cuadro 5. No obstante su inclusión no altera las conclusiones. 
En este punto, la experiencia española guarda un cierto paralelismo con la italiana $^{46}$. En ambos países, la necesidad de financiación del déficit hizo que sucesivos gobiernos fueran reticentes durante largo tiempo (último tercio del XIX y gran parte del $x x$ ) a disciplinar sus políticas monetarias ${ }^{47}$, exhibiendo una "laxitud monetaria específicamente mediterránea" ${ }^{48}$. Asimismo, la independencia de sus bancos centrales supuso para ambas el punto de inflexión en esa trayectoria, finalmente reconducida por el deseo de cumplir los requisitos de convergencia para acceder a la Europa del euro.

En España, como se ha comentado, el seigniorage como tal desaparece en 1984, momento en que se produce un significativo relevo en la financiación del déficit, que de ser esencialmente cubierto con el recurso al banco emisor, pasa a serlo mediante emisión de deuda en forma títulos muy líquidos, que entraron a formar parte de los llamados Otros Activos Líquidos (OAL). De hecho, tal fue el auge de los OAL que en el propio año 1984 las autoridades monetarias se vieron obligadas a cambiar la definición del agregado monetario objetivo intermedio, de M3 (efectivo más depósitos) a los ALP (M3 más OAL), al dejar de considerarse la primera representativa del volumen de liquidez existente en la economía. Ya para terminar, nuestro interés está en acotar la posible relación entre saldo presupuestario y ALP, interés que ya dijimos no puede resolverse de modo inmediato, por cuanto las propiedades de ambas series son diferentes. Mientras la variación de la base era claramente $\mathrm{I}(0)$ o estacionaria, se veía en el Cuadro 4 que el orden de integración de $d m$ resultaba más ambiguo, acercándose más a una serie I(1). De ahí que optemos por el enfoque bounds testing-ARDL para contrastar la existencia de una relación de equilibrio en el largo plazo entre el saldo presupuestario $b$ y la variación del agregado ALP $d m$ y estimar los parámetros que la definen ${ }^{49}$.

46 Aunque pueden encontrarse en la literatura empírica internacional numerosos trabajos sobre la relación entre finanzas públicas y dinero, sólo para el caso italiano se ha contrastado para un periodo de tan largo plazo la hipótesis de dominio fiscal. Para un panorama sobre evidencia empírica internacional acerca de la relación entre presupuesto, dinero y precios, véase Escario (2010).

$47 \quad$ En concreto, Favero y Spinelli (1999), en su análisis del periodo 1875-1994, confirmaron la endogeneidad del crecimiento del dinero con respecto al déficit público hasta 1975. Sin embargo, no funcionaba al extenderlo incluyendo lo que llamaron el 'divorcio' entre el Tesoro y el Banco de Italia en 1981, año en que el banco central se hizo independiente. En la misma línea, Fratianni y Spinelli (2001) obtuvieron evidencia a favor del vínculo entre el déficit y el componente público de la base monetaria para el periodo que va de la unificación política (1861) hasta la integración de la lira en la UEM (1998). En coherencia con Favero y Spinelli (1999), detectaron un debilitamiento del vínculo a partir de los 80. Finalmente, la necesidad de alcanzar los requisitos de Maastricht en los 90 hizo que la relación invirtiera entonces la dirección de causalidad.

48 Véase Gadea et al. (2009).

49 Desarrollado por Pesaran y Shin (1999) y Pesaran, Shin y Smith (2001). 
Esta metodología contrasta la existencia de una relación entre variables descrita por un modelo VAR expresado en forma de MCE (mecanismo de corrección de error) condicional de la forma:

$$
d d m_{t}=\alpha^{\prime} D+\pi_{1} d m_{t-1}+\pi_{2} b_{t-1}+\sum_{i=1}^{p-1} \psi_{i}^{\prime} d Z_{t-i}+\delta^{\prime} d b_{t}+\varepsilon_{t}
$$

donde $D$ es el vector de componentes determinísticos; $d Z$ incluye los retardos de $d d m$ y $d b ; \pi_{1}$ y $\pi_{2}$ son los multiplicadores de largo plazo de $d m$ y $b$, respectivamente; $\psi$ representa los coeficientes dinámicos de corto plazo y $\delta$ define la relación contemporánea con $d b$.

El procedimiento de contraste depende de la especificación que se haga del componente determinístico del modelo a estimar. En el caso que nos ocupa queda descartada la inclusión de una tendencia en el ECM, lo cual restringe el análisis a los casos I, II y III ${ }^{50}$. En la práctica, se realiza un contraste conjunto sobre los coeficientes de largo plazo de las variables independientes, donde la hipótesis nula es la no-existencia de relación de largo plazo, esto es, $H_{0}: \pi_{1}=\pi_{2}=0$ en [4] frente a la alternativa $H_{1}: \pi_{1} \neq 0$ o $\pi_{2} \neq 0$. Al no conocerse con certeza si el orden de integración de las series es $\mathrm{I}(0)$ o $\mathrm{I}(1)$ se ofrecen dos sets de valores críticos, uno para cada caso extremo: "todas las variables son I(0)" y "todas las variables son I(1)". Así, si el estadístico resultante cae por encima del límite superior de la banda de valores críticos se rechazará la hipótesis nula, mientras que si cae por debajo del límite inferior no se podrá rechazar. En caso de que cayese dentro de ella, no podría inferirse nada concluyente y se requeriría mayor información sobre el orden concreto de integración de las variables.

Los resultados que se exponen en el Cuadro 7 ofrecen conclusiones interesantes. En primer lugar, queda clara la existencia de una relación de largo plazo entre ambas variables ( $d m$ y $b$ ) a lo largo de todo el periodo muestral. Los bounds tests son muy concluyentes y la hipótesis nula de que no existe relación en niveles se rechaza al nivel del 5\%. Este descubrimiento se hace incluso más evidente cuando se aplica el F-bounds test en modelos con término independiente.

50 Pesaran et al. (2001) proponen cinco posibles modelos. Caso I: sin término independiente ni tendencia; caso II: término independiente restringido y sin tendencia; caso III: término independiente sin restringir y sin tendencia; caso IV: término independiente sin restringir y tendencia restringida; caso V: término independiente y tendencia sin restringir. Todos pueden contrastarse mediante un estadístico $F$, y los casos I, III y V también con el $t$ de Wald. Los puntos críticos de ambos se encuentran tabulados en Pesaran et al. (2001). 


\section{CUADRO 7}

BOUNDS TESTING DE LA RELACIÓN DE LARGO PLAZO ENTRE SALDO PRESUPUESTARIO Y VARIACIÓN DEL AGREGADO ALP

\begin{tabular}{cccccc}
\hline & \multicolumn{3}{c}{ con término independiente } & \multicolumn{2}{c}{ sin término independiente } \\
\cline { 2 - 6 } & $\mathrm{F}_{\mathrm{II}}$ & $\mathrm{F}_{\mathrm{III}}$ & $\mathrm{t}_{\mathrm{III}}$ & $\mathrm{F}_{\mathrm{I}}$ & $\mathrm{t}_{\mathrm{I}}$ \\
\hline $\mathbf{1 8 7 4 - 1 9 9 8}$ & $9,49^{\mathrm{c}}$ & $9,48^{\mathrm{c}}$ & $-3,06^{\mathrm{b}}$ & $4,96^{\mathrm{c}}$ & $-2,21^{\mathrm{b}}$ \\
\hline
\end{tabular}

Notas: ${ }^{a}$ indica que el estadístico se sitúa por debajo del límite inferior de la banda de valores críticos, ${ }^{\mathrm{b}}$ indica que el estadístico se encuentra dentro de la banda de valores críticos, $\mathrm{y}^{\mathrm{c}}$ indica que cae por encima del límite superior de la banda, todo ello bajo un nivel de confianza del $5 \%$. Ambos criterios de información, AIC y SBIC, seleccionan 1 retardo, comenzando por un máximo de 4 .

El siguiente paso, tras confirmar la existencia de una relación de largo plazo entre las variables saldo presupuestario y variación del agregado ALP, es examinar los parámetros que la definen. Para ello se utiliza el enfoque ARDL (AutoRegressive Distributed Lags) propuesto por Pesaran y Shin, que permite obtener por mínimos cuadrados estimaciones consistentes de los coeficientes de largo plazo sin importar si los regresores son $\mathrm{I}(0)$ o I $(1)^{51}$.

El modelo ARDL $\left(p, q_{1}, q_{2}, \ldots, q_{k}\right)$ a estimar según esta metodología es

$$
\phi(L, p) y_{t}=\sum_{i=1}^{\mathrm{k}} \beta i\left(L, q_{i}\right) x_{i t}+\delta^{\prime} w_{t}+u_{t}
$$

donde:

$$
\begin{aligned}
& \phi(L, p)=1-\phi_{1} L-\phi_{2} L^{2}-\ldots-\phi_{p} L^{p} \\
& \beta i\left(L, q_{i}\right)=1+\beta_{i 1} L+\beta_{i 2} L^{2}+\ldots+\beta_{i q_{i}} L^{q_{i}}, \text { para } i=1,2, \ldots, k
\end{aligned}
$$

$L$ es un operador de retardos tal que $L y_{t}=y_{t-1}, \mathrm{y} w_{t}$ el vector de variables determinísticas (término independiente, dummies, tendencia). Aquí, las variables $y_{t}$ y $x_{i t}$ se corresponden con el incremento del agregado monetario $d m$ y el saldo presupuestario $b$, respectivamente, mientras que la variable $w_{i t}$ incluye, además de una constante, las dummies dCuba, dMor1 y dMor 2 que cubren los episodios bélicos con Cuba (189698) y Marruecos (1909-11 y 1921-22). Teniendo en cuenta el orden del modelo ARDL (columna derecha del Cuadro 8), seleccionado mediante el criterio de SBIC, la ecuación a estimar se concreta en:

$$
d m_{t}=\phi_{1} d m_{t-1}+\phi_{2} d m_{t-2}+\beta_{0} b_{t}+\beta_{1} b_{t-1}+\delta^{\prime} w_{t}+u_{t}
$$

$51 \quad$ Pesaran y Shin (1999). 
donde el parámetro de largo plazo objeto de estudio es:

$$
\hat{\theta}=\frac{\beta_{0}+\beta_{1}}{1-\phi_{1}-\phi_{2}}
$$

CUADRO 8

ESTIMACIONES DE LARGO PLAZO DE LA RELACIÓN ENTRE SALDO PRESUPUESTARIO

Y VARIACIÓN DEL AGREGADO ALP

\begin{tabular}{ccccccc}
\hline & $\hat{\theta}$ & $\mathbf{c}$ & dCuba & dMor1 & dMor2 & ARDLmodel \\
\hline \multirow{2}{*}{$\mathbf{1 8 7 4 - 1 9 9 8}$} & $-2,06$ & 0,05 & 0,44 & 0,06 & $-0,24$ & \multirow{2}{*}{$(2,1)$} \\
& $(0,081)$ & $(0,100)$ & $(0,037)$ & $(0,679)$ & $(0,202)$ & \\
\hline
\end{tabular}

Notas: $p$-values entre paréntesis. El criterio SBIC selecciona los órdenes del modelo ARDL.

El coeficiente que representa la relación de largo plazo resulta significativo a un nivel de confianza del 8\%, con el signo negativo esperado. El siguiente paso, toda vez que se ha establecido la existencia de una relación negativa de largo plazo entre el saldo y la variación de los ALP, es aplicar el enfoque LA-VAR (lag-augmented $V A R)$, que contrasta la dirección de la causalidad entre variables cuyo orden de integración es incierto ${ }^{52}$. Para ello se emplea un modelo $\operatorname{VAR}(p+1)$, esto es, un modelo VAR cuyo orden excede al orden más alto de integración de las variables $(p)$; aunque posteriormente sólo se aplica el test de Wald a los coeficientes de esos primeros $p$ retardos. Concretando en el presente caso, se ha implementado un VAR bivariante de orden 2 (ya que el orden de las series es, como máximo, 1) en el que el test de causalidad de Wald se aplica al coeficiente del primer retardo de la variable $b$ en la ecuación de $d m$.

Los resultados ofrecidos en el Cuadro 9 muestran una concluyente dirección de causalidad del saldo presupuestario hacia la variación de los ALP — en cambio nunca se rechaza $H_{0}$ en la dirección contraria bajo niveles convencionales de confianza- Matizando algo más en el Cuadro 10, se observa que aunque la causalidad se acepta con rotundidad a lo largo del periodo completo, hacia el final del mismo la intensidad del vínculo se debilita, al igual que ocurría con la relación saldo presupuestario y base monetaria. La diferencia estriba en que aquí la causalidad permanece relativamente estable cuando el periodo 1874-1984 se amplía hasta 1874-1991, algo perfectamente coherente con la proliferación de activos líquidos con que se financió el déficit, toda vez que se renuncia al seigniorage, en la segunda mitad de los ochenta.

52 Enfoque desarrollado por Toda y Yamamoto (1995) y Dolado y Lütkepohl (1996). 
CUADRO 9

RELACIÓN DE CAUSALIDAD ENTRE SALDO PRESUPUESTARIO Y VARIACIÓN DEL AGREGADO ALP

\begin{tabular}{ccc}
\hline & $\boldsymbol{b}_{\boldsymbol{t}-\mathbf{1}} \rightarrow \boldsymbol{d \boldsymbol { m } _ { \boldsymbol { t } }}$ & $\boldsymbol{d \boldsymbol { m } _ { t - 1 } \rightarrow \boldsymbol { b } _ { \boldsymbol { t } }}$ \\
\hline \multirow{2}{*}{$\mathbf{1 8 7 4 - 1 9 9 8}$} & 10,07 & 2,45 \\
& $(0,002)$ & $(0,118)$ \\
\hline
\end{tabular}

Notas: Se ha aplicado el test de Dolado y Lütkepohl (1996) en un modelo VAR (2). Se han incluido en la parte determinística las dummies dCuba, dMor1 y dMor2.

CUADRO 10

ESTIMACIÓN RECURSIVA DE LA CAUSALIDAD DEL SALDO PRESUPUESTARIO HACIA LA VARIACIÓN DEL AGREGADO ALP

\begin{tabular}{ccc}
\hline Causalidad: $\boldsymbol{b}_{\boldsymbol{t}-\mathbf{1}} \boldsymbol{\rightarrow} \boldsymbol{d \boldsymbol { m } _ { \boldsymbol { t } }}$ & Test de Wald & $\boldsymbol{p}$-value \\
\hline $\mathbf{1 8 7 4 - 1 9 8 4}$ & 10,68 & 0,001 \\
$\mathbf{1 8 7 4 - 1 9 9 1}$ & 10,68 & 0,001 \\
$\mathbf{1 8 7 4 - 1 9 9 8}$ & 10,07 & 0,002 \\
\hline
\end{tabular}

Notas: Ver Cuadro 9.

\section{Conclusiones}

En este trabajo se ha examinado la relación entre presupuesto y dinero en España durante la práctica totalidad del periodo en que la peseta fue su moneda nacional: desde la consecución del privilegio de monopolio de emisión de billetes por parte del Banco de España en 1874, hasta el traspaso de sus responsabilidades monetarias en favor del Banco Central Europeo en 1998. La hipótesis de partida, bien asentada en la literatura económica sobre la España contemporánea, es que de forma recurrente los avatares presupuestarios condicionaron el devenir monetario español.

Evidencia a favor de esa relación la hallamos en la activa y sostenida contribución del componente público a la variación de la base monetaria. Así, se aprecia una coincidencia de déficit y aumento de la base monetaria y su componente público en 1874-1898, y luego, una coincidencia entre el dominio de superávit y el descenso de la base y su componente público en 1899-1913. No obstante, a partir de 1913, surge en los análisis un interesante problema cuantitativo. Si bien la literatura sigue apuntando al déficit como responsable destacado de la expansión monetaria, esa responsabilidad no parece tener un reflejo directo en la base monetaria española en 19141935. La explicación apunta a que los déficit pasaron entonces a financiarse mediante la colocación de deuda entre suscriptores privados, quienes rápidamente 
los pignoraban en el instituto emisor. Si sumamos al componente público la creación privada de liquidez por pignoración, entonces, de nuevo, se recupera la coincidencia de movimientos entre presupuesto y dinero en 1914-1935. Una coincidencia que sigue presente en la autarquía franquista, periodo en que se continuó utilizando el mecanismo de pignoración, hasta que en 1959 el Plan de Estabilización y Liberalización le puso fin. De 1942 hasta ese año, la pignoración actuó como un potente instrumento de creación de liquidez, lo que sumado al recurso directo del Tesoro al Banco de España, explicaría una expansión monetaria muy por encima de lo que había sido la dinámica (excluyendo coyunturas bélicas) de años anteriores.

Sin embargo, la presunta presión monetaria del déficit no acabó con la eliminación de la deuda pignorable. A mediados de los años sesenta, el deterioro de las cuentas públicas se reflejó en una contribución directa del sector al crecimiento de la base y, de nuevo en los setenta, se registra una confluencia de déficit, crecimiento de la base monetaria y su componente público. Esa confluencia se acentúa de 1977 en adelante, momento en que la combinación de transición política, implementación del Estado del Bienestar y crisis económica recrudece el problema del déficit, financiado hasta 1984 con el recurso directo al Banco de España. A partir de ese año, la contribución pública al crecimiento de la base monetaria se diluye definitivamente, en línea con el cambio de pautas en la financiación del déficit. El déficit pasa entonces a financiarse a través de la emisión de títulos de deuda, sin reflejo, por tanto, en la base monetaria, aunque en su condición de títulos de muy corto plazo, contribuyó destacadamente al crecimiento del agregado ALP hasta 1989.

En resumen, el cálculo de la contribución (más o menos velada) del componente público al crecimiento de la base monetaria y de la contribución de la deuda al crecimiento de los ALP, apoya la idea de que el presupuesto condicionó de manera recurrente la evolución del dinero en la España de la peseta. Una idea que este trabajo confirma en términos dinámicos, en cuanto halla una relación de largo plazo entre saldo presupuestario y base monetaria y saldo presupuestario y ALP para el conjunto del período 1874-1998, siempre con el sentido de causalidad claramente definido de la primera a las segundas variables. Además, la intensidad del vínculo entre déficit y base monetaria se debilita de 1984 en adelante, acusando la por entonces renuncia a seguir financiando el déficit con recurso directo al Banco de España y el fin del seigniorage. Sin embargo, también de acuerdo con la literatura, hallamos que la intensidad del vínculo entre déficit y ALP no registra inflexión alguna en los ochenta, en consonancia con la proliferación de títulos de deuda a corto plazo que, emitidos para financiar el déficit, computan en el agregado. De hecho, el vínculo entre presupuesto y ALP (dinero en sentido amplio) no se debilita hasta que en los noventa, en la recta final por cumplir los requisitos de convergencia nominal, las necesidades de financiación pública retroceden y, con ellas, la emisión de títulos a corto. 
El resultado final es bien conocido. El cumplimiento del requisito de inflación (un diferencial de menos de 1,5\% sobre la media de los tres países menos inflacionistas) y del requisito de déficit público (por debajo del 3\% del PIB) supuso la entrada de España a la UME en 1998. Atrás quedaba la peseta y, con ella, más de cien años de recurrente injerencia presupuestaria en el terreno monetario. Paradójicamente, la ejecución monetaria española lograba independizarse de las injerencias fiscales, con el tiempo justo para ceder su autonomía a Europa.

\section{Bibliografía}

ANES ÁLVAREZ, Rafael (1974a): “Una serie de base monetaria (1874-1915)”, en TORTELLA, Gabriel (dir.), La Banca española en la Restauración, Vol. II: Datos para una historia económica, Madrid, Servicio de Estudios del Banco de España, pp. 199-209.

-(1974b): "Estimación de la moneda de plata existente en España entre 1874 y 1915", en TORTELLA, Gabriel (dir.), La Banca española en la Restauración, Vol. II: Datos para una historia económica, Madrid, Servicio de Estudios del Banco de España, pp. 99-116.

-(1974c): "Balances Sectorizados del Banco de España (1874-1915)”, en TORTELLA, Gabriel (dir.), La Banca española en la Restauración, Vol. II: Datos para una historia económica, Madrid, Servicio de Estudios del Banco de España, pp. 141-198.

ARÍZTEGUI, Francisco Javier (1988): "La política monetaria”, en GARCÍA DELGADO, José Luis (dir.) España. Economía, Madrid, Espasa Calpe, pp. 903-926.

ARÍZTEGUI, Francisco Javier (1990): “La política monetaria: un periodo crucial” en GARCÍA DELGADO, José Luis (dir.), Economía española de la transición y la democracia, Madrid, CIS, pp. 307-341.

AYUSO, Juan y ESCRIVÁ, José Luis (1997): “La evolución de la estrategia de control monetario en España", en SERVICIO DE ESTUDIOS DEL BANCO DE ESPANA, La política monetaria y la inflación en España, Madrid, Alianza Editorial, pp. 89-120.

BANCO DE ESPAÑA (1959): La situación monetaria y financiera, Madrid, 1959.

-(1982): Boletín Estadístico - Series Históricas 1962-1981.

-(varios años): Boletín Estadístico.

-(varios años): Informe Anual.

BARCIELA, Carlos; LÓPEZ, María Inmaculada; MELGAREJO, Joaquín y MIRANDA, José Antonio (2001): La España de Franco (1939-1975), ed. Síntesis, Madrid.

CARRERAS, Albert y TAFUNELL, Xavier (2004): Historia Económica de la España Contemporánea, Crítica. 
CARRERAS, Albert; PRADOS DE LA ESCOSURA, Leandro y ROSÉS, Joan (2005): "Renta y riqueza", en CARRERAS, Albert y TAFUNELL, Xavier (eds.), Estadísticas Históricas de España, siglos XIX-XX, Fundación BBVA, Madrid, pp. 12971376.

COMÍN, Francisco y DÍAZ, Daniel (2005): "Sector público y estado del bienestar", en CARRERAS, Albert y TAFUNELL, Xavier (eds.), Estadísticas Históricas de España, siglos XIX-XX, Fundación BBVA, Madrid, pp. 873-964.

DOLADO, Juan José y LÜTKEPOHL, Helmut (1996): “Making Wald Test Work for Cointegrated VAR Systems", Econometrics Reviews, 15, pp. 369-386.

DOMÍNGUEZ MARTÍNEZ, José Manuel (1990): “La financiación del Tesoro Público por el Banco de España”, Papeles de Economía Española, 43, pp. 120-143.

ESCARIO, Regina (2010, en prensa): "Presupuesto, dinero y precios: un panorama”, Revista de Economía Mundial.

FAVERO, Carlo y SPINELLI, Franco (1999): “Deficits, Money Growth and Inflation in Italy: 1875-1994", Economic Notes, 28 (1), pp. 43-71.

FLORES DE LEMUS, Antonio (1929): “Dictamen de la Comisión nombrada por Real Orden de 9 de enero de 1929, para el estudio de la implantación del patrón oro", Información Comercial Española, 318, 1960, pp. 51-83.

FRATIANNI, Michele y SPINELLI, Franco (2001): “Fiscal Dominance and Money Growth in Italy: the Long Record", Explorations in Economic History, 38 (2), pp. 252-272.

FUENTES QUINTANA, Enrique (1984): “El Plan de Estabilización económica de 1959, veinticinco años después", Información Comercial Española, 612-613, pp. 25-40.

-(1995): El modelo de economía abierta y el modelo castizo en el desarrollo económico de la España de los años 90, Prensas Universitarias de Zaragoza.

-(1996): "El déficit público como problema de nuestro tiempo", Anales de la Real Academia de Ciencias Morales y Políticas, 73, pp. 419-444.

-(2004): “Los Pactos de la Moncloa y la Constitución de 1978”, en FUENTES QUINTANA, Enrique (dir.), Colección Economía y economistas españoles - La economía como profesión, vol. 8, Galaxia Gutemberg, pp. 163-238.

GADEA, María Dolores; BEN-KAABIA, Monia y SABATÉ, Marcela (2009): “Exchange rate regimes and prices. The cases of Italy, Spain and United Kingdom (18741998)", Journal of International Financial Markets, Institutions and Money, 19(3), pp. 477-489.

GONZÁLEZ, Manuel Jesús (1979): La economía política del franquismo (1940-1970), Madrid, Tecnos.

GRANGER, Clive (1969): “Investigating Casual Relations by Econometric Models and Cross-Spectral Methods", Econometrica, 37, pp. 424-438.

-(1988): "Some Recent Developments in a Concept of Causality", Journal of Econometrics, 39, pp. 199-211. 
LÜTKEPOHL, Helmut (1991): Introduction to Multiple Time Series Analysis, Berlin: Springer-Verlag.

MALO DE MOLINA, José Luis (2003): “Una visión macroeconómica de los veinticinco años de vigencia de la Constitución Europea", Revista de Economía Industrial 349/350, Economía y Constitución - XXV Aniversario, Ministerio de Ciencia y Tecnología, pp. 29-50.

MARÍN, José y PEÑALOSA, Juan (1997): “Implicaciones del marco institucional y la política presupuestaria para la política monetaria en España”, en SERVICIO DE ESTUDIOS DEL BANCO DE ESPAÑA. La politica monetaria y la inflación en España, Madrid, Alianza Editorial, pp. 181-221.

MARTÍN ACEÑA, Pablo (1985a): “Déficit público y política monetaria en la Restauración, 1874-1913", en MARTÍN ACEÑA, Pablo y PRADOS DE LA ESCOSURA, Leandro (eds.), La nueva historia económica en España, Madrid, Editorial Tecnos, pp. 262-284.

-(1985b): La cantidad de dinero en España, Madrid, Banco de España.

-(1988): Una estimación de los principales agregados monetarios en España: 1940-1962, Madrid, Banco de España.

-(1994): "Los problemas monetarios al término de la Guerra Civil”, Hacienda Pública, 2, pp. 63-88.

MARTÍNEZ MÉNDEZ, Pedro (1981): El control monetario a través de la base monetaria: la experiencia española, Madrid, Banco de España.

McKINNON, James (1996): “Numerical Distribution Functions for Unit Root and Cointegration Tests", Journal of Applied Econometrics, 11(6), pp. 601-18.

NEWEY, Whitney y WEST, Kenneth (1994): "Automatic Lag Selection in Covariance Matrix Estimation", Review of Economic Studies, 61, pp. 631-653.

NG, Serena y PERRON, Pierre (1995): “Testing for Unit Roots in Flow Data Sampled at Different Frequencies", Economics Letters, 47, pp. 237-242.

OLARIAGA, Luis (1933): La política monetaria en España, Lib. V. Suárez, Madrid.

ORTEGA, Raimundo (1984): “El déficit público y su financiación”, Hacienda Pública Española, 88, pp. 22-47.

-(1987a) (ed.): Escritos (1948-1980), Madrid, Banco de España.

-(1987b): "Un repaso histórico al recurso del Tesoro al crédito del Banco de España", Hacienda Pública Española, 107, pp. 181-205.

PESARAN, M. Hashem y SHIN, Yongcheol (1999): “An Autoregressive Distributed Lag Approach to Cointegration Analysis", en STORM, S. (ed.), Econometrics and Economic Theory in the 20 $0^{\text {th }}$ Century: The Ragnar Fisch Centennial Symposium, Cambridge University Press, capítulo 11.

PESARAN, M. Hashem; SHIN, Yongcheol y SMITH, Richard J. (2001): “Bounds Testing Approaches to the Analysis of Level Relationships", Journal of Applied Econometrics, 16, pp. 289-326. 
POVEDA, Raimundo (1972): La creación de dinero en España 1956-1970. Análisis y política, Madrid, Ministerio de Hacienda, Instituto de Estudios Fiscales.

-(1980): "Los circuitos privilegiados del sistema crediticio", Papeles de Economía Española, 3, pp. 114-135.

REPULLO, Rafael (1990): “La reforma de los coeficientes bancarios en España”, Papeles de Economía Española, 43, pp. 107-119.

ROJO, Luis Ángel y PÉREZ, José (1977): La política monetaria en España: Objetivos e instrumentos, Madrid, Banco de España.

ROJO, Luis Ángel (2002): “La economía española en la democracia (1976-2000)”, en COMÍN, Francisco; HERNÁNDEZ, Mauro y LLOPIS, Enrique (eds.), Historia económica de España. Siglos X-XX, Crítica, pp. 397-436.

-(2004): "El largo camino de la política monetaria española hacia el euro", en FUENTES QUINTANA, Enrique (dir.), colección Economía y economistas españoles - La economía como profesión, vol. 8, Galaxia Gutemberg, pp. 349-366.

SABATÉ, Marcela; GADEA, María Dolores y ESCARIO, Regina (2006): “Does Fiscal Policy influence Monetary Policy? The Case of Spain, 1874-1935", Explorations in Economic History, 43 (2), pp. 309-331.

SÁNCHEZ ASIAÍN, José Ángel (1999): Economía y finanzas en la Guerra Civil española (1936-1939), Real Academia de la Historia, Madrid.

-(2003): Larraz y la tormenta monetaria del 36, Papeles y Memorias de la Real Academia de las Ciencias Morales y Políticas, Madrid.

SARDÀ, Joan (1970): “El Banco de España (1931-1962)”, en BANCO DE ESPAÑA, El Banco de España. Una historia económica, Madrid, pp. 419-479.

TODA, Hiro y YAMAMOTO, Taku (1995): "Statistical inference in vector autoregressions with possibly integrated processes", Journal of Econometrics, 66, pp. 225250. 